\title{
OPTIMIZATION OF HYBRID ENERGY STORAGE SYSTEM PROVIDING POWER CURVE SMOOTHENING IN GRID SCALE
}

By

Gouri Rani Barai

M.Eng., Asian Institute of Technology, Thailand, 2010

B.Sc., American International University - Bangladesh, Bangladesh, 2007

\author{
A Thesis \\ Presented to Ryerson University \\ in Partial Fulfillment of the Requirements for the \\ Degree of Master of Applied Science \\ in the Program of \\ Electrical and Computer Engineering
}

Toronto, Ontario, Canada, 2016

(C) (Gouri Barai) 2016 


\section{Author's Declaration}

I hereby declare that I am the sole author of this thesis. This is a true copy of the thesis, including any required final revisions, as accepted by my examiners.

I authorize Ryerson University to lend this thesis to other institutions or individuals for the purpose of scholarly research.

I further authorize Ryerson University to reproduce this thesis by photocopying or by other means, in total or in part, at the request of other institutions or individuals for the purpose of scholarly research.

I understand that my thesis may be made electronically available to the public. 


\begin{abstract}
Thesis Title: Optimization of Hybrid Energy Storage System Providing Power Curve Smoothening in Grid Scale

Degree: Master of Applied Science

Convocation Year: 2016

Student Name: Gouri Rani Barai

Graduate Program: Electrical and Computer Engineering

University: Ryerson University
\end{abstract}

Efficient supply of electric energy, maintaining power quality, and addressing intermittency of renewable energy and unpredictable demand fluctuations are challenges of a modern power grid. An individual energy storage technology seldom provides all the desired characteristics expected. A Hybrid Energy Storage System (HESS) including different types of energy storage systems can address these challenges.

In this work a new formulation and algorithm was developed that optimally designs a grid-scale HESS for desired performances such as peak load shaving and power demand curve smoothening at the least capital cost. The proposed HESS comprised of a combination of Lithium lon batteries, Flywheels, and Ultracapacitor based Energy Storage Systems. Real and synthetic power demand dataset representing different types of demand fluctuations were used in the analysis. The proposed formulation and algorithm was able to optimally size HESS such that it costs the least while performing in the desired manner. 


\section{ACKNOWLEDGEMENTS}

I would like to thank my supervisors Dr. Bala Venkatesh and Dr. Sri Krishnan for giving me the opportunity to pursue my graduate studies at the Department of Electrical and Computer Engineering at Ryerson University. I am greatly indebted to Dr. Venkatesh for his continuous encouragement, support and guidance given during the course of this project. It was a great honour for me to work under his supervision.

Financial supports from the Centre of Urban Energy and the Department of Electrical and Computer Engineering are greatly acknowledged.

I like to extend my gratitude to Dr. Kaamran Raahemifar, Dr. Bin Wu, Dr. David Xu and Dr. Amirnaser Yazdani. I have learned a great deal of power system engineering from them. I also like to thank Dr. Lian Zhao for her encouragement at different professional activities. I also thank my colleagues and friends at the CUE.

I thank my family members for their support and encouragement to reach to the end line. 


\section{DEDICATION}

"Dedicated to mother, father and my mother-in-law" 


\section{TABLE OF CONTENTS}

Title Page

$$
\text { i }
$$

Author's Declaration Page ii

Abstract iv

Acknowledgement vi

Dedication vii

Table of Contents viii

List of Tables $\quad$ xi

List of Figures $\quad$ xii

Nomenclature xiv

1 Introduction $\quad 1$

$\begin{array}{lll}1.1 & \text { Introduction } & 1\end{array}$

1.2 Survey of Recent Work 2

1.3 Motivation and Objective of the Thesis 3

1.3.1 Motivation 3

1.3.2 Objectives 4

1.4 Thesis Organization 4

2 Literature Review $\quad 6$

2.1 Introduction 6

2.2 Energy Storage $\quad 6$

$\begin{array}{lll}2.3 & \text { Hybrid Energy Storage System(HESS) } & 10\end{array}$

$2.4 \quad$ Flywheel 12

$\begin{array}{lll}2.5 & \text { Capacitor and Ultracapacitor } & 15\end{array}$

$\begin{array}{lll}2.6 & \text { Battery } & 19\end{array}$

$2.7 \quad$ Lithium-ion Battery 20

$2.8 \quad$ Some Examples of Storage Systems Grid Scale Application 22

$2.9 \quad$ Selection of Energy Storage Systems for HESS 24

2.10 Chapter Summary 26 
3 Proposed Model and Formulation

$\begin{array}{lll}3.1 & \text { Introduction } & 27\end{array}$

$\begin{array}{lll}3.2 & \text { Nomenclature } & 27\end{array}$

3.3 Objective Function and Constraints 28

$\begin{array}{lll}3.4 & \text { Chapter Summary } & 31\end{array}$

4 Analyses and Results $\quad 32$

$\begin{array}{lll}4.1 & \text { Introduction } & 32\end{array}$

4.2 Selection of MATLAB Solvers: 'Fmincon', 'Patternsearch' and 'Genetic 32 Algorithm'

4.3 Optimization Problem Solution with Real Power Demand Data 33

4.3.1 Algorithm for Data Case 1

4.3.2 Power Demand Data for Data Case 1

4.3.3 Effects of Different Parameters for Data Case 1

4.4 Optimization Problem Solution for Power Demand Data Created with 42 Different Magnitude of Demand Fluctuations: Data Case 2

4.4.1 Power Demand Data for Data Case 2

4.4.2 Algorithm for Data Case $2 \quad 44$

4.4.3 Effects of Different Parameters: Data Case 2

4.5 Sensitivity Analysis $\quad 51$

4.6 Chapter Summary 53

5 Conclusions and Recommendations $\quad 55$

5.1 General 55

5.2 Chapter-wise Summary 55

5.2.1 Chapter 1: Introduction 55

5.2.2 Chapter 2: Literature Review 55

5.2.3 Chapter 3: Proposed Model and Formulation 55

5.2.4 Chapter 4: Analyses and Results 56

5.3 Contributions: Key Findings and Important Discovery 57

$\begin{array}{lll}5.4 & \text { Recommendations for Future Work } & 57\end{array}$

$\begin{array}{lr}\text { References } & 59\end{array}$ 


\section{LIST OF TABLES}

$2.1 \quad$ Comparison of Different Types of Capacitors 15

$\begin{array}{lll}2.2 & \text { Commercially Available Supercapacitors } & 18\end{array}$

2.3 Different Types of Rechargeable Batteries and Their Comparison 20

$2.4 \quad$ Comparison between Battery, Flywheel, and Supercapacitor 24

4.1 Parameters for Li-ion Batteries, Flywheels, and Ultracapacitors 36

4.2 Optimized Results with Power Demand Data Scaling 42

4.3 Impacts of Various Cost Parameters of Different Storage Systems on the Total Cost of 52 HESS 


\section{LIST OF FIGURES}

2.1 Classification of Energy Storage According to Energy Form 9

2.2 Energy Storage Technologies in Terms of System Power Rating vs Discharge Time at 9 that Rated Power

2.3 Comparison of Energy Storage Systems 11

2.4 Comparison of Energy Storage Systems with respect to Runtime vs Cost 11

$2.5 \quad$ Internal Construction of a Flywheel 12

2.6 A Supercapacitor from Maxwell Technologies 15

2.7 Conventional Capacitor (a) vs Supercapacitor (double-layer) (b)(working principle) 16

2.8 Typical Charge-discharge Curve of Battery (MPV = Mid-point Voltage and EODV= End 19 of Discharge Voltage)

2.9 Schematic diagram of Cylindrical Liquid Li-ion Cell and Prismatic polymer Li-ion Cell $\quad 20$

$\begin{array}{ll}2.10 & \text { Working Principle of Li-ion Battery }\end{array}$

$2.1120 \mathrm{MW}$ Beacon Flywheel power plant, Stephentown, NY 23

2.12 The Tappi Wind Park Advanced Lead Acid Battery System (by Hitachi) 23

2.13 AES Storage LLC's Laurel Mountain Li-ion Energy Storage (32MW) 24

3.1 Proposed Hybrid Energy Storage System 27

4.1 Actual Power Demand Curve and the Reference Power Curve 34

4.2 Power Flow From and To HESS. Power Demand Data was Scaled to 1/50th. Peaks 35 above the Red Line is for HESS Discharging and the Peaks below are for HESS Charging

4.3 Change in Total Cost per Year with Increased Number of System for Each Type (ND) as well as Increased Number of System Types (NT). (Power Data was of the $11^{\text {th }}$ Hour and Scaled to $\left.1 / 50^{\text {th }}\right)$

4.4 Variation in (a) Optimum Energy (EEmax), (b) Optimum Power (PEmax) of Battery, Flywheel, and Ultracapacitor, and (c) Total Cost per Year with the Change in Standard Deviation of Power Demand Data. The Power Demand Data is Scaled to 1/50th and Number of System for Each Type was $1(N D=1)$

4.5 Variation in (a) Optimum Energy (EEmax), (b) Optimum Power (PEmax) of Battery, Flywheel, and Ultracapacitor, and (c) Total Cost per Year with the Change in Frequency of Power Demand per Hour. The Power Demand Data is Scaled to 1/50th and Number of System for Each Type was $1(N D=1)$

4.6 Change in Total Cost with Change in Flywheel Constant and Battery Constant for: (a) 40 1x Rated Power of Battery and Flywheel and (b) 3x Rated Power of Battery and Flywheel. Constant Value of 142088 is the Average of Battery and Flywheel Constants. Number of System for Each Type is $2(N D=2)$ and Power Data was of the 11th Hour 
4.7 Change in Total Cost per Year with Change in Constant (Keeping Battery Constant and Flywheel Constant Same for Each Case) for $1 x$ (orange bars) and 3x (blue bars) of the Rated Power of Battery and Flywheel. Number of System for Each Type is $2(N D=2)$ and Power Data was of the 11th Hour

4.8 Four Cases of Power Flow Data of HESS (red bars) and Energy of HESS in Each Time Step of 15 Minutes (Blue line): Case: A (0/150), Case: B (50/100), Case: C (100/50) and Case: D (150/0)

4.9 Change in Total Cost per Year for Different Ratios of Power Demand Change in Slow Cycles and Fast Cycles for Number of Type of Systems, $N T=3(F+B+C$, Flywheel + Battery + Ultracapacitor; Red bars), $N T=2$ (F+B, Flywheel + Battery; Blue bars), $N T=1$ (F, Flywheel; Blue bars), and $N T=1$ (B, Battery; Blue bars) (Number of Each Type of System, $N D=1$ )

4.10 Change in Total Cost per Year for Different Ratios of Power Demand Change in Slow Cycles and Fast Cycles for Number of Type of Systems, $N T=2(\mathrm{~F}+\mathrm{B}$, Flywheel + Battery; Blue bars) and $N T=3(\mathrm{~F}+\mathrm{B}+\mathrm{C}$, Flywheel + Battery + Ultracapacitor; Red bars):

(a) Number of Each Type of System, ND = 1 and (B) Number of Each Type of System, $N D=2$

4.11 Variation in Optimum Maximum Power (PEmax) of Flywheel, Battery and Ultracapacitor with the Variation of Power Demand Fluctuation for $N T=3$

4.12 Variation in Optimum Maximum Power (PEmax) of Flywheel, Battery and Ultracapacitor with the Variation of Power Demand Fluctuation for $N T=2$

4.13 Variation in Optimum Maximum Energy (EEmax) of Flywheel, Battery and Ultracapacitor with the Variation of Power Demand Fluctuation for $N T=3$

4.14 Variation in Optimum Maximum Energy (EEmax) of Flywheel, Battery and Ultracapacitor with the Variation of Power Demand Fluctuation for $N T=2$

4.15 Variation in Number of Cycle per 12 Hours of Each Energy Storage System when HESS Consists of Flywheel, Battery and Ultracapacitor with the Variation of Power Demand Fluctuation for $N T=3$

4.16 Variation in Number of Cycle per 12 Hours of Each Energy Storage System when HESS Consists of Flywheel and Battery with the Variation of Power Demand Fluctuation for $N T=2$

4.17 Variation in Depth of Discharge of Each Energy Storage System when HESS Consists of Flywheel, Battery, and Ultracapacitor with the Variation of Power Demand Fluctuation for $N T=3$

4.18 Variation in Depth of Discharge of Each Energy Storage System when HESS Consists of Flywheel and Battery with the Variation of Power Demand Fluctuation for NT=2

4.19 Variation of Total Cost per Year with Varying Cost Parameters of Flywheel Systems. (Power Data Scaled Down to $1 / 50^{\text {th }}$ ) 


\section{NOMENCLATURE}

$\begin{array}{ll}\text { A_cost } & \text { Purchasing cost of a system } \\ \text { B_cost } & \text { Power cost of a system } \\ \text { C_cost } & \text { Energy cost of a system } \\ \text { PE } & \text { Output Power of each system } \\ \text { EE } & \text { Energy output of each system } \\ \text { PT } & \text { Total power required form HESS at a specific time } \\ \text { PER } & \text { Ramp rate } \\ \text { GW } & \text { Gigawatt } \\ \text { MW } & \text { Megawatt } \\ \text { KW } & \text { Kilowatt } \\ \text { IESO } & \text { Independent Electricity System Operator } \\ \text { UC } & \text { Ultracapacitor } \\ \text { SOC } & \text { State of charge } \\ \text { ESS } & \text { Energy Storage System } \\ \text { HESS } & \text { Hybrid Energy Storage System } \\ \text { DOD } & \text { Depth of Discharge } \\ \text { NC } & \text { Number of charge-discharge cycle per year } \\ \text { NY } & \text { Life time of a system at rated DOD } \\ \text { Li-ion } & \text { Lithium ion battery }\end{array}$




\section{Chapter 1}

\section{INTRODUCTION}

\subsection{Introduction}

The modern society cannot be imagined without the electric energy. Over many decades significant improvements occurred in different areas of power systems. However, the electric power grid still has some challenges to overcome, such as energy efficiency, reliability, stability, and consistency. In addition, the effects of some of these challenges are increasing day by day with the increment in number of consumers and variations in energy production and consumption [Carnegie, 2013; Parfomak, 2012]. When electricity originates as AC power it cannot be stored directly. One of the main challenges is the storage inability of AC form electricity that leads to the necessity of consumption at the moment of production and vice-versa [IEC, 2010]. Therefore, the electric systems need to be balanced continuously for the supply of electricity and the demand at that moment [Teleke, 2014]. This balancing activities in power systems have significant impacts on the operation and cost. The main challenges of the modern power systems that need to be addressed are: high cost for peak generation, intermittency of renewable energy, unpredictable demand fluctuation, frequency regulation, fossil fuel dependency, etc. [Carnegie, 2013, Bhuiyan and Yazdani, 2012; Xie, 2015].

Energy storage systems can store electric energy (ac form) by converting to other form (depending on the type of the system) for later use. These storage systems can offer efficient power management improving the power quality of the grid along with transient stability and supply reliability [Ribeiro, 2001; Gupta, 2011]. The general benefits of the application of energy storage systems in power grid are: supply for peak demands; efficient supply for demands that change quickly and that are constrained by generation and transmission systems; support for grid ancillary services, such as, frequency regulation and power quality improvement with efficient and reliable operation; integration of distributed and intermittent renewable energy resources into the electricity supply systems [Carnegie, 2013; Jiang, 2012; Parfomak, 2012; Ye, 2014]. 
Over the last century, many types of energy storage technologies have been developed. These technologies utilize chemical, mechanical, electrochemical, thermal principles for storing one type of energy into other forms [Carnegie, 2013]. The storage technologies have received significant interest in recent decades due to increase in fossil fuel cost, the necessity of improving power system quality and stability, integration of new renewable energy sources, necessity of solutions to electric transportation systems, etc. [IEC, 2010; Kintner-Meyer, 2012; USDOE, 2013]. With this renewed interest in energy storage systems, significant improvements have been achieved in the storage systems, such as increase in conversion efficiency, increase in power and energy density, increase in delivery speed, longer life cycle, and decrease in cost [Rastler, 2010]. Despite such improvements in individual storage technologies, the applications are still limited due to the lack of versatility of a single type of storage system. In addition, these storage systems are required to provide various services [Shin, 2011]. Only one type of energy storage system cannot provide all the services required for the power grid. This leads to the idea of using a combination of number of energy storage systems with different characteristics to work together compensating each other's drawbacks and sustain the power quality of the grid [Akhil, 2013; IEC, 2010; Khaligh, 2010; Kim, 2012]. This combined system is known as Hybrid Energy Storage System (HESS).

\subsection{Survey of Recent Work}

A detailed literature survey was conducted on the energy storage systems (e.g., battery, flywheel, ultracapacitors), their characteristics, limitations, grid scale applications, and potential roles in the proposed HESS are presented in Chapter 2.

A significant number of studies are found in the literature that incorporated one type or a combination of two types of energy storage technologies. Most of these works are related to integration of intermittent renewable energy plants (mainly photovoltaic and wind energy) in smaller scale grid [Quanyuan, 2012; Chen 2014] or microgrid [Weiqing, 2012; Setyawan, 2015], electric vehicle [Ostadi, 2013], and distributed energy storage systems [Pegueroles-Queralt, 2015]. These studies mainly used a combination of battery and ultracapacitor [Allegre, 2010; 
Shen, 2014; Zhuge, 2014]. However, there is a lack of research work combining three or more types of energy storage systems for application in larger grids. Some literature survey works are available; however, very limited or none on the system optimization. A recent report on storage systems' applications at grid scale have pointed out that advanced software tools would be required to perform detailed analysis of different types of storage technologies that optimize multiple services for proper valuation of the storage systems [Denholm, 2013]. However, proper software tools capable of analyzing and optimizing hybrid energy storage systems incorporating multiple storage technologies in grid scale are also lacking.

In this thesis, a combination of three types of energy storage systems are considered for use in large scale grid, such as Ontario power grid. In addition, this system is open for inclusion of more types of energy storage systems. In this case each storage system is considered as a generator, which stores energy buying as a consumer when demand is lower than generation, and supplies as a generator when demand is higher than generation. Any smaller fluctuations in demand is considered to be supplied by these storage systems to smooth the generation curve maintaining the demand-supply balance.

\subsection{Motivation and Objective of the Thesis}

\subsubsection{Motivation}

Lithium Ion batteries offer high power and energy performance at high costs. Flywheels offer high power and low energy capabilities at moderate costs. Ultracapacitors provide very high power capabilities at low energy capacities and their costs increase with increase in energy capacity. No one type provides all the desired performance at a reasonable costs. Hybrid Energy Storage Systems (HESS) can be created that combines these individual technologies of various sizes such that desired performance is obtained at the least cost. The challenge to develop an algorithm that can design such a system is the motivation for this thesis. 


\subsubsection{Objectives}

The main objective of this thesis is to optimize the configuration of a hybrid energy storage system (HESS) for grid scale application providing requisite service. The specific objectives are:

a) To optimally design a HESS consisting of one or more types of energy storage systems (Liion battery, Flywheels, and Ultracapacitors) capable of providing power and energy to a power grid meeting any sudden increment of power demand for a short duration and offering generation and load curve smoothening. To this end, develop an optimization formulation with an objective of minimizing the total per year asset cost of the HESS, subject to a set of constraints related to the specifications and capacities of the selected energy storage systems.

b) To perform the effect of Cycle life of each energy storage system on total annual asset cost of HESS and perform sensitivity analysis for several cost parameters and system operation parameters to identify their impacts on the total cost per year of the HESS. In addition, to determine the effects of power demand change rate, number of types of systems in HESS and number of systems of each type on the total annual asset cost of HESS, maximum operation power and energy, number of cycles, and depth of discharge of each type of storage systems.

\subsection{Thesis Organization}

This thesis contains six chapters. The contents of these chapters are briefly described below:

1) Introduction - The ideas that lead to this thesis are discussed in this chapter along with the objective and scope of the work.

2) Literature Review - This chapter presents a comprehensive literature survey on various energy storage systems, their characteristics, and grid scale applications. The potential role of the selected energy storage systems in the proposed hybrid energy storage systems are explained. 
3) Proposed Model and Formulation - The formulation of the optimization problem to optimize the design of storage systems and the related constraints are explained in detail in this chapter.

4) Analyses and Results - The power demand data analysis and artificial power demand data creation, optimization problem solutions using two power demand data cases are described in this chapter. In addition, sensitivity analysis results for several cost and operational parameters are presented with pertinent discussions.

5) Conclusions and Recommendations - This chapter summarizes the key findings and observations; states the key findings and important observations; and suggests recommendations for future work. 


\section{Chapter 2}

\section{LITERATURE REVIEW}

\subsection{Introduction}

Energy storage systems (ESSs) store the excess energy generated due to low demand than generation by converting it to another suitable form for later use by the consumer load devices during more demand than generation [Boicea,2014; Carpenter, 2012; Smith, 2008]. At Present, this is a challenge to increase the energy efficiency, reliability, and consistency of the power grid. Another challenge is the unpredictability reduction and efficiency increment of the renewable power sources [Xie, 2015]. Using hybrid energy storages systems (HESSs) that consist of various different types of energy storage elements is a promising and doable solution. This enables a cost-effective (in the long run) and energy-efficient approach by fully exploiting the strengths of different energy storage technologies to compensate each other's drawbacks [Kim, 2012] through appropriate charge management processes that includes charge replacement, allocation, and migration [Wang, 2011; Xie, 2011; Xie, 2012]. HESS increases the energy efficiency of the grid by proper energy management, peak shaving, load balancing, and so on [Mirhoseini, 2011; Shin, 2011]. It removes the intermittency of renewable sources by storing the excess generated energy to extract and utilize the maximum power from the sources [Kim, 2010].

This chapter focuses on the detailed description of energy storage systems and hybrid energy storage system. A HESS model is proposed and its elements (Battery: Lead-acid and Lithium-ion, Supercapacitor or ultracapacitor, and Flywheel), application of these elements, comparison of their characteristics, roles of these elements in the HESS system are summarized in this chapter.

\subsection{Energy Storage}

Energy storage is a process of storing energy for later use. The energy can be stored in many different forms. A medium that stores energy as chemical (e.g., batteries)/thermal/mechanical (e.g., flywheel)/electrical (e.g., capacitor) or other forms such as compressed air to use at later 
time when needed is known as energy storage system [Brown, 2015]. Storing capacity of an energy storage system is measured in watt-hours (Wh). For example, a battery with an energy storage capacity rating of 1,000 watt-hours can provide power to either 1,000 watts capacity device for 1 hour or a 1 watt capacity device for 1,000 hours or a 50 watts capacity device for 20 hours.

Some major applications of energy storage in power system are listed below [Akhil, 2013, McCluer, 2015]:

a. Power stability - When the main power supply of power transmission and distribution (T\&D) system is unstable (e.g., power surges and sags), energy storage system can provide the needed energy to stabilize the disturbances assuring a smooth power supply to the load.

b. Power bridging - Energy storage system can provide needed energy to assure steady power during switching (from seconds to hours) from one source of power to another (e.g., utility power to generator power)

c. Energy management/Electric Energy Time-shift (Arbitrage) - Electric energy timeshift means purchasing electric energy during off peak hour when price or system market price is low to recharge the storage system and use the stored energy later when the electricity market price or cost is high. In this process necessity of peak generators can be reduced or removed. To serve for this purpose some technical requirements of the storage device are required to be fulfilled, such as System Size Range: 1 - 500 MW; Target Discharge Duration Range: $<1$ hour; Minimum Cycles/Year: $250+$.

d. Regulation - Energy storage system can supply power during momentary differences caused by fluctuations in generation and loads and support frequency regulation. Sudden very small change in demand can be provided by energy storage system without affecting the supply power resulting in supply stability.

e. Renewable energy sources - Energy storage system can store the energy generated by renewable energy plants connected to the grid and use it later when needed. It will balance the generation and demand supply from renewable energy sources 
[Denholm, 2010; Smith, 2010; Shively, 2008]. Energy storage systems can increase the efficiency of renewable power plant and ensure the stability, reliability, flexibility and power quality of the grid [ECOFYS, 2014; Etxeberria, 2010].

f. Transmission and distribution deferral: ESS can perform the function of T\&D (Transmission\& Distribution) reducing the necessity of new T\&D [Teleke, 2014].

g. Spinning reserve: ESS can perform the operations of operating reserves.

h. Voltage support: ESS can maintain the desired voltage level of the grid.

i. Reduce greenhouse gas emission: ESS reduces the increase of use of fossil fuel indirectly.

In addition, an energy storage system acts as a potential source of energy to supply during sudden interruption to the regular electrical flow. It also addresses the challenges of a rapid switchover to an alternative power source when a power disturbance occurs, ramping limitation of generators during rapid demand change, and the stable delivery of power [Anees, 2012] to the load until the disturbance is resolved [Carnegie, 2013]. Energy storage system can affect the energy market [Goulding, 2013; Zareipour, 2007] by working as a generating power source and supply peak load reducing the dependency on fossil fuel. Figure 2.1 presents different types of energy storage system. Figure 2.2 presents comparison of different energy storage systems according to their maximum power rating and discharge rate. This comparison chart helps the decision making of storage system selection for different applications [Akhil, 2013]. 


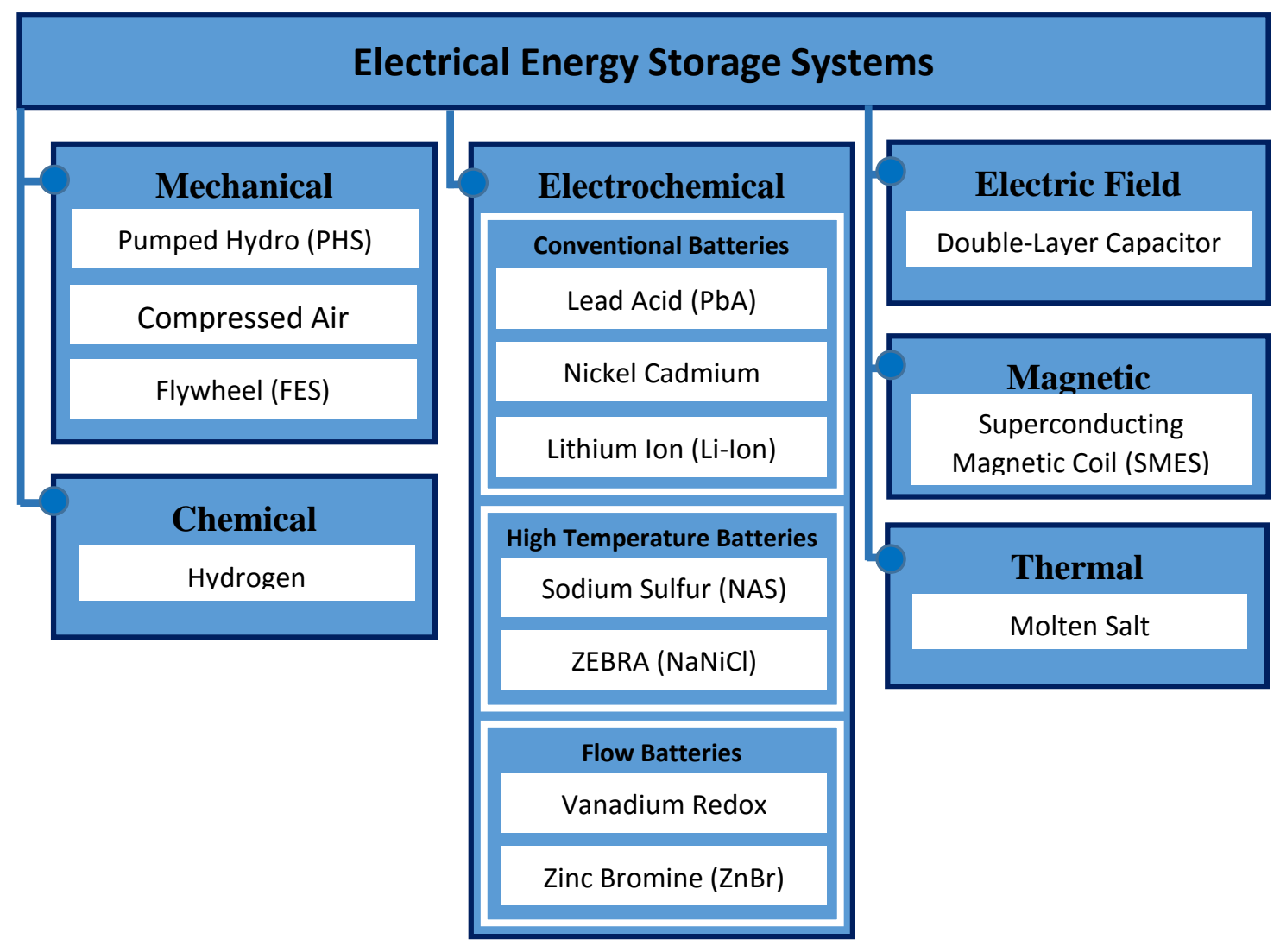

Figure 2.1 Classification of Energy Storage According to Energy Form. Adopted from [Carnegi, 2013]

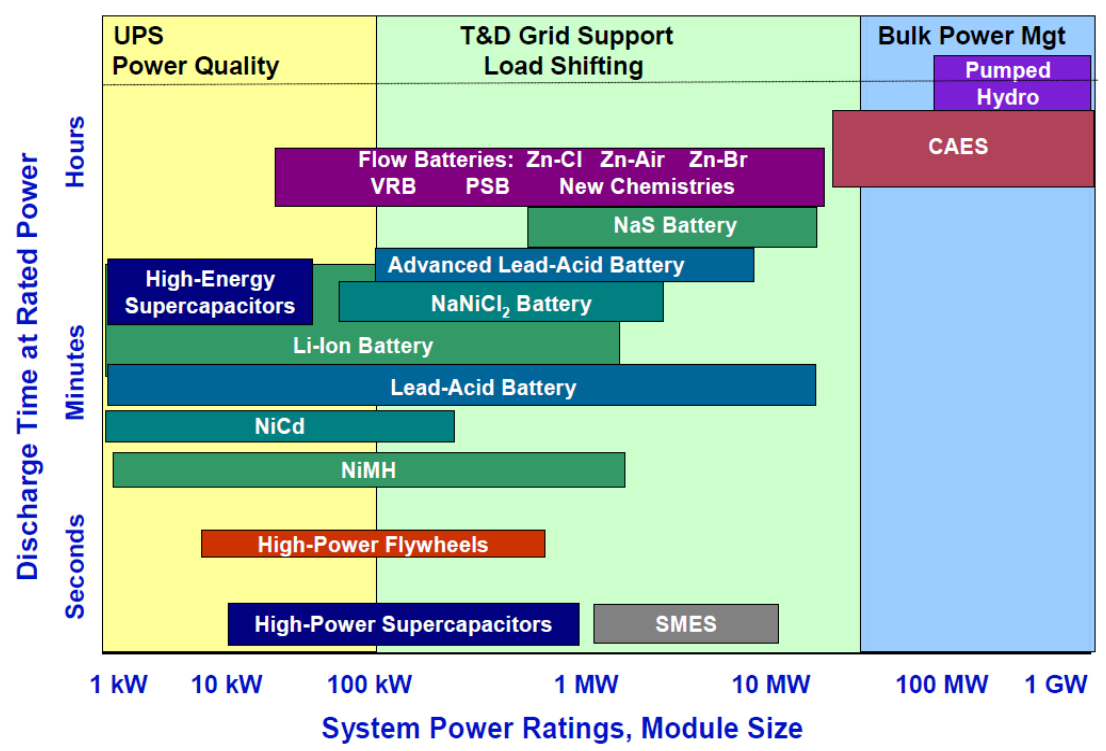

Figure 2.2 Energy Storage Technologies in Terms of System Power Rating vs Discharge Time at that Rated Power. Image taken from [Akhil, 2013]. 


\subsection{Hybrid Energy Storage System (HESS)}

Different energy storage systems has different characteristics which make them preferable for different applications. However, a single type of energy storage system cannot show high energy density, high power delivery capacity, low cost per unit of storage, long cycle life, low leakage, and so on at the same time. Multiple benefits can be achieved with the combination of a number of energy storage systems [Deepthi, 2015] and it is known as hybrid energy storage system [Etexberria, 2012; Pedram, 2010]. In power system, when there is sudden sharp change in the demand lasting for few seconds (generator cannot supply right away due to ramping limitation), the battery (more energy density, less power density) will not be a suitable choice as it takes more time to discharge [Wang, 2014]. But an ultracapacitor (more power density, very less energy density) can discharge in seconds and hence a good option for this case [Guerrero, 2009; Weiqing, 2012]. Again Flywheel is safer in case of maintenance than ultracapacitor and can also discharge in seconds [Siostrzonek, 2008]. When a system contains all of these three energy storage elements, the application will not be limited but versatile and more reliable. The combination is named as hybrid energy storage system. In this thesis work a hybrid energy storage system with these three types of energy storage elements is considered and therefore, these storage elements are discussed in detail in the remaining of this Chapter.

Figure 2.3 represents the comparison of battery, flywheel and ultracapacitor in terms of runtime vs cost. It is clear that flywheel is the heaviest and largest one whereas lithium-ion battery is the lightest and smallest energy storage device [Horiba, 2014]. Figure 2.4 represents the comparison of battery, flywheel and ultracapacitor in terms of runtime vs cost. It shows that ultracapacitor can discharge in seconds but battery can discharge for a longer period [Meena, 2014]. But more runtime costs more. 


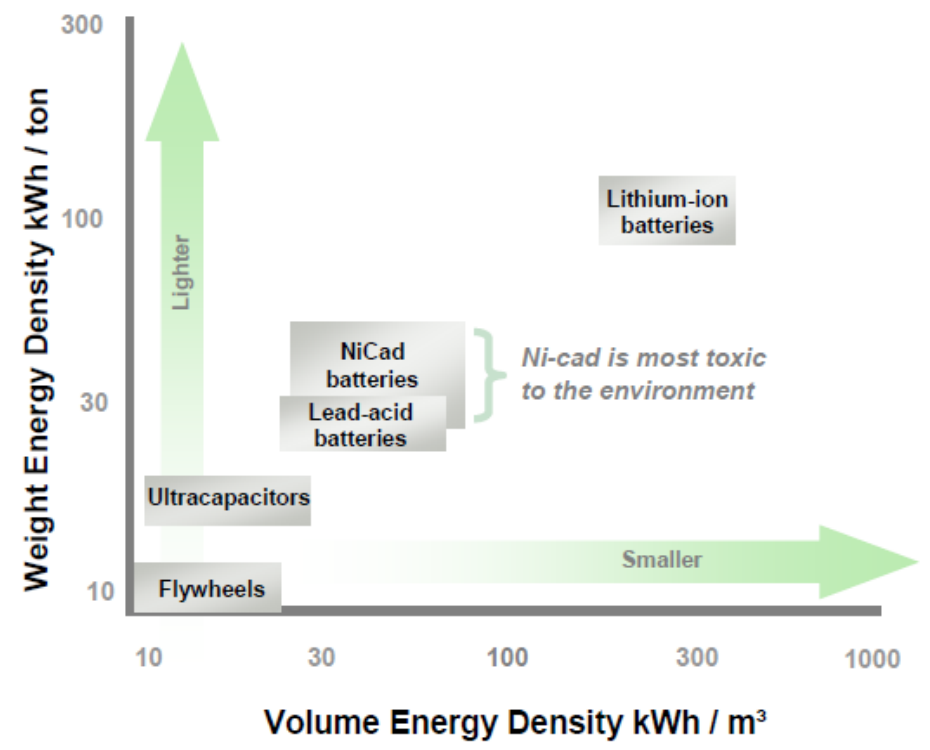

Figure 2.3 Comparison of Energy Storage Systems. Image taken from [McCluer, 2015].

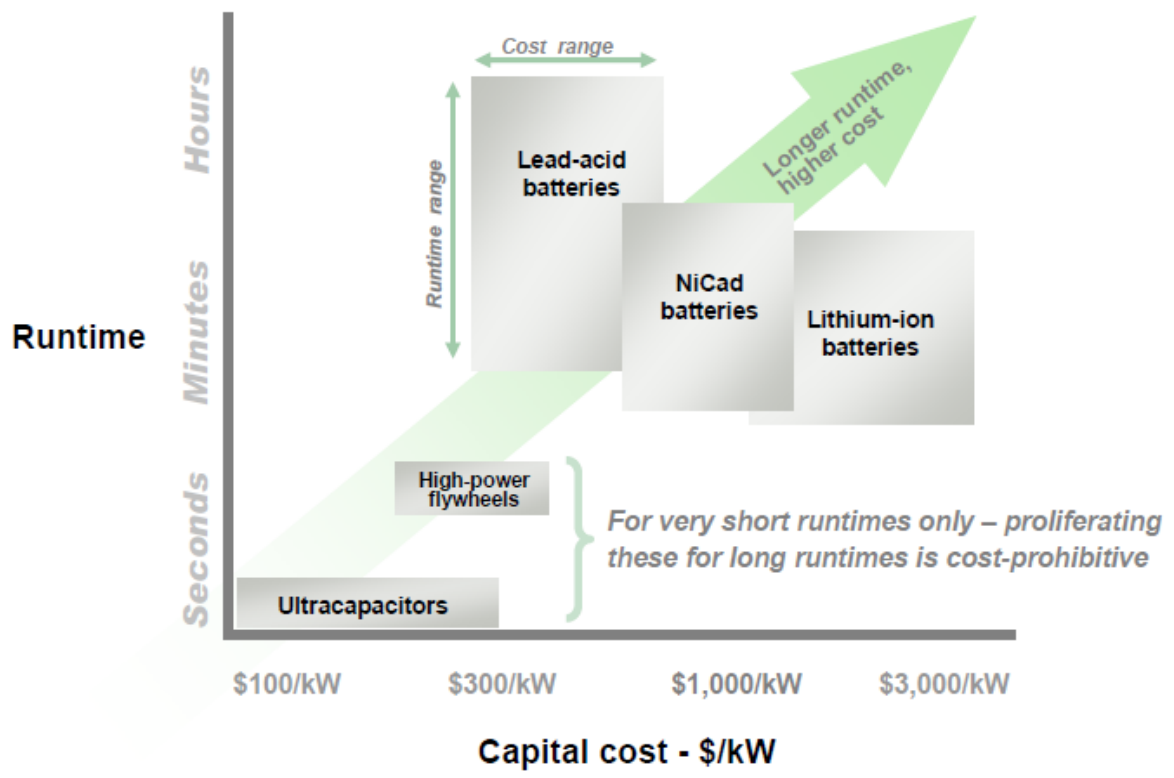

Figure 2.4 Comparison of Energy Storage Systems with Respect to Runtime vs Cost. Image taken from [McCluer, 2015]. 


\subsection{Flywheel}

A Flywheel is a rotating device which stores energy in kinetic form. It stores mechanical energy from electrical energy and when needed can supply back electrical energy. It is connected to the supply point (grid) through a bidirectional power converter which can convert AC/DC according to the necessity. This type of energy storage system is most suitable in case of sudden change in power (kilowatt to few megawatt, KW to MW) in seconds and if it occurs hundreds or thousands time staying for a very short period [Pena-Alzola, 2011]. Flywheel is not limited by number of cycles and can be discharged very fast (within seconds). Power system deals with gigawatts (GW) of power in grid and small changes also mean in MW range. But it is not possible to achieve MW of power with a single flywheel unit due to constraint of materials, size and cost. By connecting a number of flywheel units together, a Flywheel energy storage system is constructed to achieve the required higher power range accepting all constraint [Zhou, 2014]. In this report, a Flywheel module /system represents a number of Flywheels together which can charge (store) and discharge (release) at high power rating in very short period of time [Tseng, 2010].

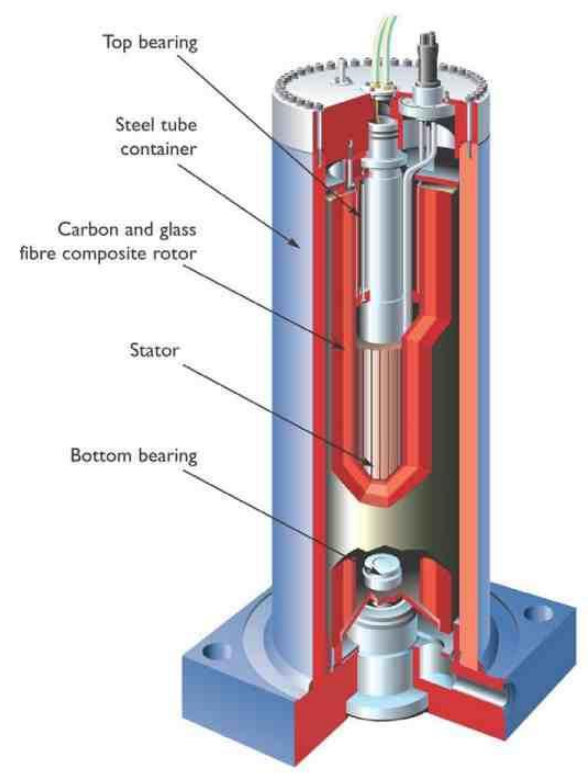

Figure 2.5: Internal Construction of a Flywheel. Image taken from [KTS, 2015]. 
A Flywheel is a heavy wheel (rotor) typically placed in a vacuum chamber to reduce frictional loss and connected to the grid by a bidirectional power converter through a motor-generator machine. It charges as a load to supply as a source. The rotor takes a lot of force to spin and according to the law of conservation of angular momentum, it has a tendency to keep its current angular momentum (spinning state) due to its moment of inertia. So energy is stored in kinetic form.

Kinetic energy of a rotating Flywheel can be expressed as [4]:

$$
E=\frac{1}{2} \mathrm{~J} \omega^{2}
$$

where, $\mathrm{J}=$ moment of inertia and $\omega=$ angular velocity.

Moment of inertia, J, is expressed as:

$$
\mathrm{J}=m r^{2}
$$

where, $m=$ mass of the rotor and $r=$ radius of the rotor.

Angular velocity, $\omega$, is expressed as:

$$
\omega=\frac{d \theta}{d t}
$$

where, $d \theta=$ angular displacement and $d t=$ difference in time.

Angular displacement, $\theta$, can be expressed as:

$$
\theta=\frac{s}{r}
$$

where, $S=$ arc length.

Therefore, the kinetic energy of a rotating flywheel can be expressed as:

$$
E=\frac{1}{2} m r^{2} \omega^{2}
$$


Kinetic energy is directly proportional to mass of the rotor and inversely proportional to the square of the radius of the rotor. Also it increases with the increase of the angular velocity. Using heavy metal rotor increases the amount of stored energy but using light metal rotor will make it spin faster and increase the energy even more.

Advantages of Flywheel [Daoud, 2012; Zhang, 2002]:

1) Initial cost is low compared to chemical storage system

2) Almost infinite life cycle

3) Not limited in lifetime as that of batteries

4) Environmentally friendly as no harmful chemicals are used and no polluting gasses are released as by-product

5) Is not affected by the climate

6) Take less space compared to any other energy storage system

7) Highly efficient $(\approx 85 \%)$

8) Most important advantage is that it is charged and discharged very quickly (in seconds to minutes) and as a result very suitable for sudden power change systems

Limitations of Flywheel [Daoud, 2012; Zhang, 2002]:

1) Weighs more compared to other energy storage systems

2) Faces high stress and strains during spinning in very high speed

3) It cannot store large amount of energy as batteries

4) Cannot supply for a longer period of time continuously

\subsection{Capacitor and Ultracapacitor}

A capacitor is a widely used electrical component used to store energy and comprises of two plates separated by an insulating material [Bird, 2007]. All capacitors can be grouped into three categories [BU, 2015]: Electrostatic capacitor, Electrolytic capacitor, and Ultracapacitor (Supercapacitor). Table 2.1 presents a comparison of the above capacitors [BU, 2015]. 
Supercapacitor is an electric double layer capacitor [Gualous, 2002]. It is a polar device and can be defined as a combination of capacitor and battery [CU, 2015]. It is also known as ultracapacitor. It can charge and discharge very quickly and has very high storage capacity [Glavin, 2007].

Table 2.1: Comparison of Different Types of Capacitors

\begin{tabular}{|l|l|l|l||}
\hline Parameter & Electrostatic capacitor & Electrolytic capacitor & Supercapacitor \\
\hline $\begin{array}{l}\text { Storage } \\
\text { Capacitance }\end{array}$ & Very low & $\begin{array}{l}\text { Several thousand times } \\
\text { more than electrostatic } \\
\text { one }\end{array}$ & $\begin{array}{l}\text { Very high compared } \\
\text { to the other two }\end{array}$ \\
\hline Separator & Dry & Moist & Combination \\
\hline Size (rating) & $\begin{array}{l}\text { Few pico-farad (pf) to } \\
\text { low microfarad (uF) }\end{array}$ & Microfarads (uF) & Farads \\
\hline Application & $\begin{array}{l}\text { Filter signals and tune } \\
\text { radio frequencies }\end{array}$ & $\begin{array}{l}\text { Power filtering, } \\
\text { buffering and coupling }\end{array}$ & $\begin{array}{l}\text { Energy storage that } \\
\text { needs frequent } \\
\text { charge and discharge } \\
\text { at high current and } \\
\text { short duration. }\end{array}$ \\
\hline
\end{tabular}

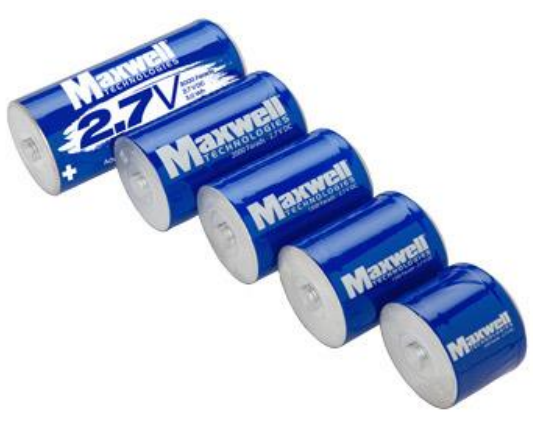

Figugre 2.6 : A Supercapacitor from Maxwell Technologies [MT, 2015]. 
Supercapacitors can be divided into three classes according its mechanism of storing electrical energy [CU, 2015; Halper, 2006]:

1) Electrochemical Double-layer capacitance - It follows a non-Faradaic process where charges are distributed on surfaces by physical processes without any chemical reaction. It can be classified further according to electrode material as activated carbons, carbon nanotubes and carbon nanogels.

2) Pseudocapacitor - It follows Faradaic processes (oxidation-reduction reactions) to transfer charge between electrode and electrolyte. It can be classifies further as conducting polymers and metal oxides according to the material of electrode.

3) Hybrid capacitors - It follows the combination of both chemical and nonchemical mechanism to store energy. It can be classified further as composite hybrids, asymmetric hybrids and also battery type hybrids can be included here.

Figure 2.7 shows the working principle of Supercapacitor in comparison with conventional capacitor [Halper, 2006]:
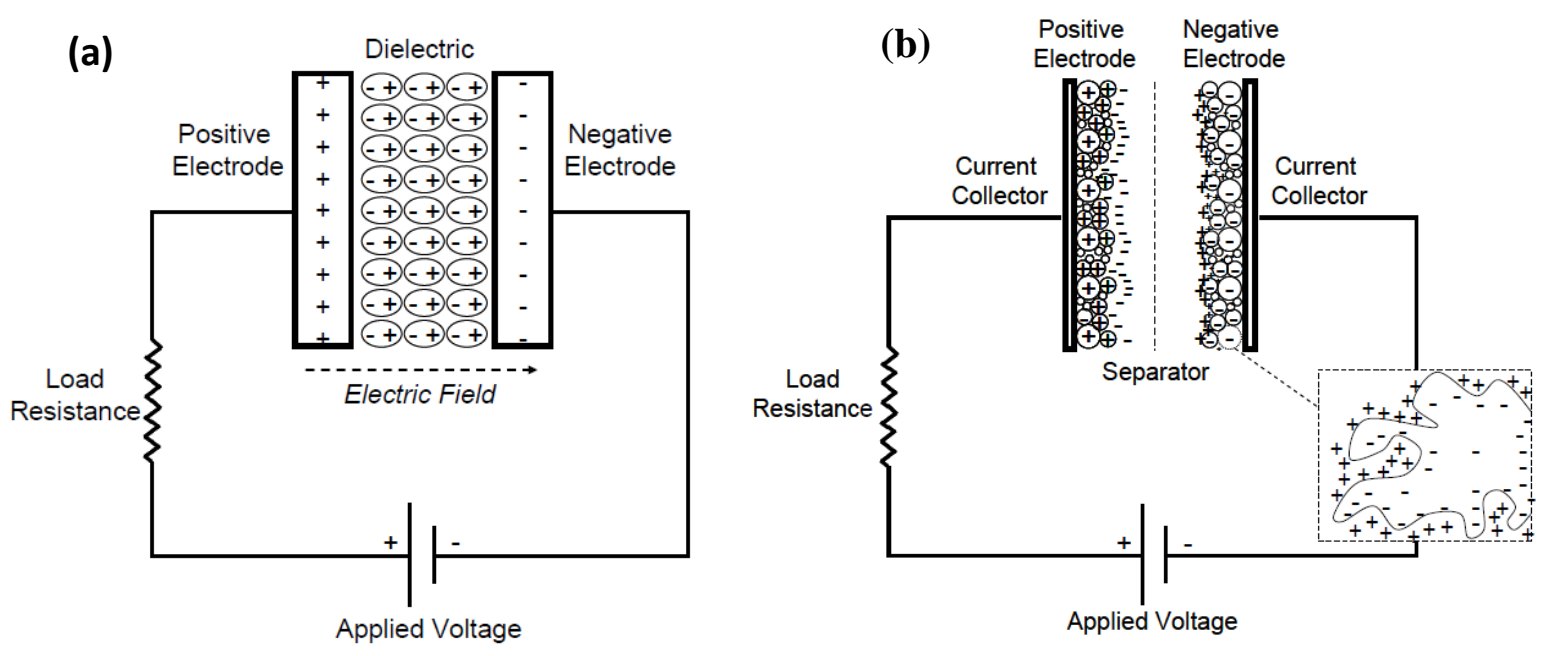

Figure 2.7: Conventional Capacitor (a) vs Supercapacitor (Double-layer) (b) Working Principles. Image taken from [Halper, 2006]. 
Working principles of Conventional Capacitors and Supercapacitors [Bird, 2007; Guerrero, 1009; Halper, 2006]:

1) Conventional capacitors are constructed of two conducting electrodes separated by an insulating dielectric material which keeps the charges separate to generate an electric field to store energy. Electrochemical double-layer capacitors (EDLCs) are constructed of two carbon-based electrodes: an electrolyte and a separator.

2) Conventional capacitors and EDLCs both store charge electrostatically.

3) There is no transfer of charge between electrode and electrolyte in EDLC resulting in highly reversible charge storage, which allows EDLC to achieve very high number of cycles.

4) With and external voltage applied, ions in the electrolyte solution diffuse across the separator into the pores of the electrode of opposite charges causing charge accumulation on the electrode surfaces. The electrodes are designed in such a way so that the ions cannot be recombined as a result a double-layer of charge is produced at each electrode.

5) The most commonly used electrode material in EDLCs is activated carbon. It uses complex porous structure to gain higher surface area.

6) In pseudocapacitors energy is stored through transfer of charge between electrode and electrolyte by electrosorption, reduction-oxidation reactions and intercalation processes. Thus pseudocapacitors have greater capacitances and energy densities than EDLCs.

Advantages of Supercapacitor [Patrick, 2015; Reddy, 2015; Xiaoliang 2013]:

1) High power density

2) Quick charging/discharging

3) Extended lifetime

4) Stops accepting energy when it becomes fully charged

5) Internal ESR is extremely small ( $\approx 0.01$ ohms)

6) Unlimited shelf life

7) No emissions (in form of gas or anything)

8) Does not blow up in case of accidental direct short connection 
9) Environmentally safe

Drawbacks of Supercapacitor [BET, 2015; FARADIGM, 2015; Patrick, 2015; Xie, 2015]:

1) Highest dielectric absorption

2) Very high self-discharge rate

3) Series connections are needed to obtain higher voltages which leads to the necessity of complex voltage balancing circuit

4) Terminal voltage and state of charge is directly proportional

5) Low energy density

6) Supplies power for very short duration

Table 2.2 shows some commercially available Supercapacitors and their capacities.

Table 2.2: Commercially Available Supercapacitors [Sahay, 2009].

\begin{tabular}{|l|l||}
\hline Manufacturer & Capacitor Rating \\
\hline Power Star China Make & $>50 \mathrm{~F} / 2.7 \mathrm{~V}$, \\
(single Unit) & $>300 \mathrm{~F} / 2.7 \mathrm{~V}$, \\
& $>600 \mathrm{~F} / 2.7 \mathrm{~V}, \mathrm{ESR}$ less than $1 \mathrm{~m} \Omega$. \\
\hline Panasonic Make & $>0.022-70 \mathrm{~F}, 2.1-5.5 \mathrm{~V}$, \\
(Single Unit) & $>\mathrm{ESR} 200 \mathrm{~m} \Omega-350 \Omega$ \\
\hline Maxwell Make & $>94 \mathrm{~F} / 75 \mathrm{~V}, 50 \mathrm{~A}, \mathrm{ESR} 15 \mathrm{~m} \Omega$ \\
(Module) & $>10-600 \mathrm{~F} / 2.3 \mathrm{~V}, \mathrm{ESR} 400-20 \mathrm{~m} \Omega, 150 \mathrm{ESR} 18 \mathrm{~m} \Omega$ \\
\hline Vinatech Make & $>3-350 \mathrm{~F} / 2.7, \mathrm{ESR} 90-8 \mathrm{~m} \Omega$ \\
& $>15 \mathrm{~V} / 33 \mathrm{~F}, \mathrm{ESR} 27 \mathrm{~m} \Omega$ \\
\hline Nesscap Make & $>340 \mathrm{~V} / 51 \mathrm{~F}, \mathrm{ESR} 19 \mathrm{~m} \Omega$ \\
\hline (module) & $>15$ \\
\hline
\end{tabular}




\subsection{Battery}

Battery is a chemical energy storing device. It takes electrical energy and stores as chemical energy. Again when needed, it supplies the stored chemical energy in electrical form. For storing energy a battery needs two or more electrochemical cells. A battery cell has three basic components: anode, cathode, and electrolyte to assist the energy flow [Bird 2007; P. Harrop]. Figure 2.8 shows the charge/discharge characteristic of a battery [RE, 2015].

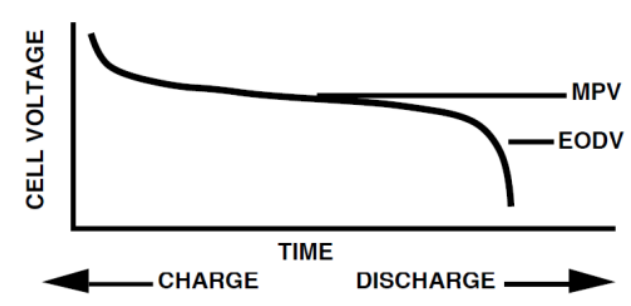

Figure 2.8: Typical Charge-discharge Curve of Battery (MPV = Mid-point Voltage and EODV= End of Discharge Voltage) [RE, 2015].

To address higher voltage demand many cells are connected in series and for higher current demand many cells are connected in parallel. Batteries are classified based on capacity, type of electrolyte, size, shape, weight, ruggedness, sate of charge (SOC), depth of discharge (DOD), thermal response, cycle life, shelf life, and cost. SOC is the percentage of charge in battery remained at present compared to the maximum capacity and DOD is the percentage of capacity that has been discharged already. Batteries can also be classified as single use and rechargeable depending on application. There are different types of rechargeable batteries used commercially at present. Table 2.3 shows a list of different types of batteries and comparison among them based on some specific parameters [AAPPC, 2015; LPF, 2015]. In this thesis rechargeable battery has been considered as an energy storage system and from this point forward the term battery will be used for rechargeable battery. 
Table 2.3: Different Types of Rechargeable Batteries and Their Comparison [AAPPC, 2015; LPF, 2015].

\begin{tabular}{|c|c|c|c|c|c|c|c|c|c|c|}
\hline Element & $\begin{array}{l}\text { Capital } \\
\text { cost } \\
\text { (\$/kWh) }\end{array}$ & $\begin{array}{l}\text { Cycle } \\
\text { efficiency }\end{array}$ & $\begin{array}{l}\text { Cycle } \\
\text { life }\end{array}$ & $\begin{array}{l}\text { Self- } \\
\text { discharge } \\
\text { per day }\end{array}$ & $\begin{array}{l}\text { Energy } \\
\text { density } \\
(\mathrm{Wh} / \mathrm{kg})\end{array}$ & $\begin{array}{l}\text { Power } \\
\text { density } \\
(W / k g)\end{array}$ & $\begin{array}{l}\text { Electrolyte } \\
\text { state }\end{array}$ & $\begin{array}{l}\text { Min. } \\
\text { thickness }\end{array}$ & $\begin{array}{l}\text { Memory } \\
\text { effect }\end{array}$ & Pollution \\
\hline $\begin{array}{l}\text { Lead } \\
\text { acid }\end{array}$ & $100-200$ & $70-90 \%$ & $500-800$ & $0.1-0.3 \%$ & $30-50$ & $75-300$ & Liquid & $>10 \mathrm{~mm}$ & NO & YES \\
\hline $\begin{array}{l}\text { NiCd } \\
\text { battery }\end{array}$ & $\begin{array}{l}800- \\
1000\end{array}$ & $70-90 \%$ & $\begin{array}{l}2000- \\
2500\end{array}$ & $0.2-0.6 \%$ & $50-75$ & $\begin{array}{l}150- \\
300\end{array}$ & Liquid & $>3 \mathrm{~mm}$ & YES & YES \\
\hline $\begin{array}{l}\text { NiMH } \\
\text { battery }\end{array}$ & $\begin{array}{l}450- \\
1000\end{array}$ & $66 \%$ & $\begin{array}{l}500- \\
1000\end{array}$ & $0.5-1 \%$ & $60-80$ & $\begin{array}{l}250- \\
1000\end{array}$ & Liquid & $>3 \mathrm{~mm}$ & NO & NO \\
\hline $\begin{array}{l}\text { Li-ion } \\
\text { battery }\end{array}$ & $\begin{array}{l}600- \\
2500\end{array}$ & $>90 \%$ & $\begin{array}{l}1000- \\
10,000+\end{array}$ & $0.1-0.3 \%$ & $100-250$ & $\begin{array}{l}250- \\
340\end{array}$ & Liquid & $>3 \mathrm{~mm}$ & NO & NO \\
\hline
\end{tabular}

\subsection{Lithium-ion (Li-ion) Battery}

Li-ion technology is comparatively new in the history of battery technology. Lithium ion is a low maintenance battery with very high energy density [Horiba, 2014]. There are different types of Li-ion cells such as, Lithium Iron Phosphate, Lithium Manganese, Lithium Polymer, Lithium Sulfur, and more.

According to construction, most commonly used Li-ion cell can be divided as cylindrical liquid Liion cell and prismatic polymer Li-ion cell [Akhil, 2013]. Figure 2.9 shows the schematic diagram of these two types of cells [Akhil, 2013]. 


\section{Schematic of Cylindrical Cell}

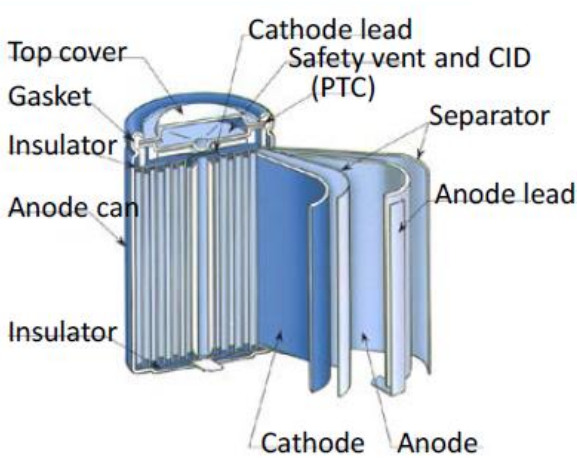

Schematic of Prismatic Cell

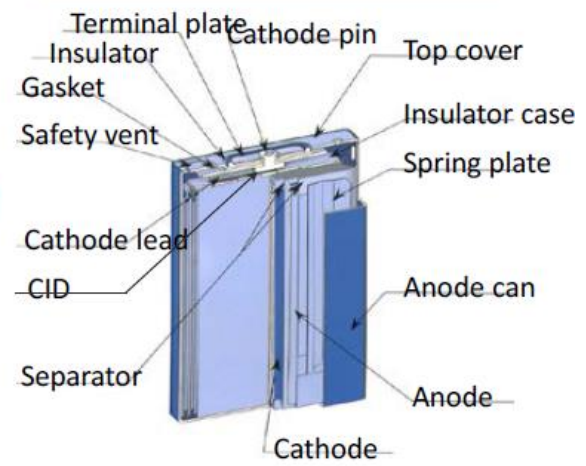

Figure 2.9: Schematic Diagram of Cylindrical Liquid Li-ion Cell and Prismatic Polymer Li-ion Cell. Image taken from [Akhil, 2013].

\section{Working Principles of Li-ion Battery}

A Li-ion cell has two reactive materials and a separator as shown in Figure 2.10. For chemical reaction (exchange of charges), these two reactive materials are connected electrically (external connection outside of the cell) to maintain flow of electrons in the external circuit and ionically (internal connection - inside the cell) to maintain flow of ions in the electrolyte. Amount of electrons must be equal to the amount of ions to sustain the balance of charges.

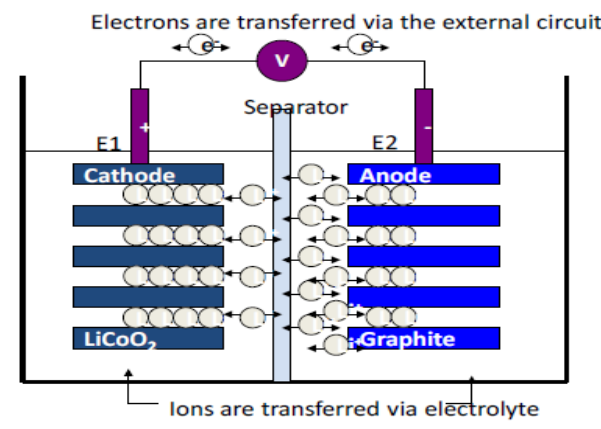

Figure 2.10: Working Principle of Li-ion Battery. Image taken from [Akhil, 2013].

\section{Advantages of Li-ion Battery [BU, 2015]:}

Li-ion Battery has a number of advantages as described below:

1) It has high energy density which is suitable for higher capacities 
2) It needs one regular charge but does not need prolonged priming when new

3) It has relatively low self-discharge which is almost half of nickel-based batteries selfdischarge

4) It has the longest lifespan compared to other batteries

$5)$ It has the largest amount of cycles $(\approx 1000-2000$ cycles) compared to the most commonly used batteries

6) It needs very low Maintenance and it does not need periodic discharge

7) It can be made to provide very high current for power applications

8) It has the lowest environmental impact compared to the type of batteries

9) It has the best energy-to-weight ratio compared to other batteries

10) Efficiency of lithium-ion batteries: Upwards of $80 \%$

\section{Limitations of Li-Ion Battery}

1) It requires protection circuit to maintain voltage and current within safe limits

2) It ages even when it is not in use and the way to reduce aging effect is to store in a cool place at $40 \%$ charge

3) It has higher manufacture cost than other type of batteries

4) It is said that the technology is not fully matured yet

\subsection{Some Examples of Storage Systems Grid Scale Application}

In Figures 2.11 to 2.13 few examples of Flywheel, Lead-acid Battery, and Li-ion energy storage systems' grid scale applications are presented. An image is not provided here; however, Japan deployed a 4MW capacity Supercapacitor systems installed in commercial buildings to reduce grid consumption at peak demand [BU, 2015]. 


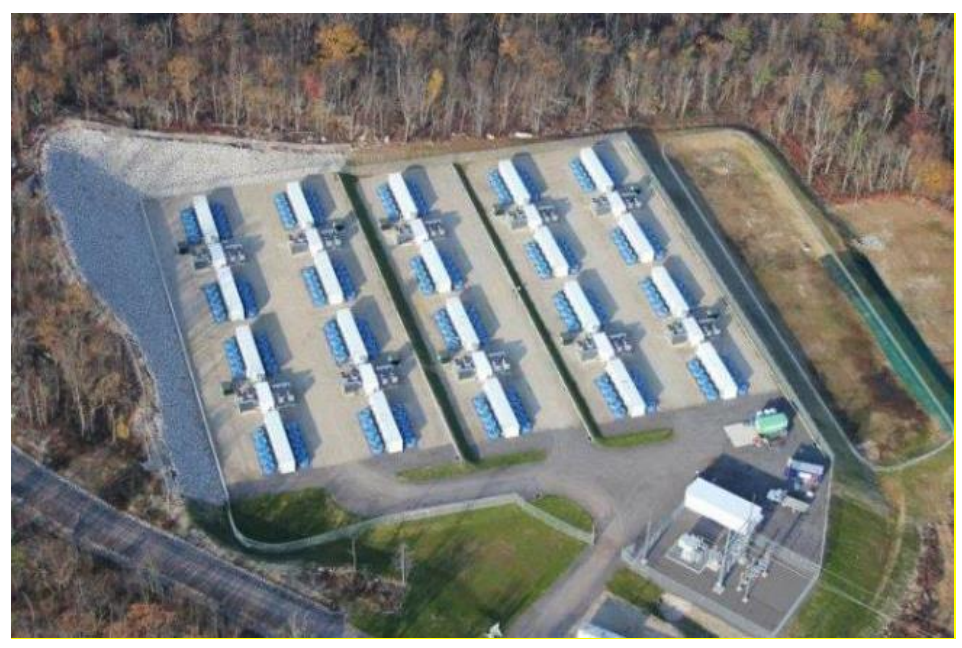

Figure 2.11: 20 MW Beacon Flywheel Power Plant, Stephentown, NY. Image taken from [Akhil, 2013].

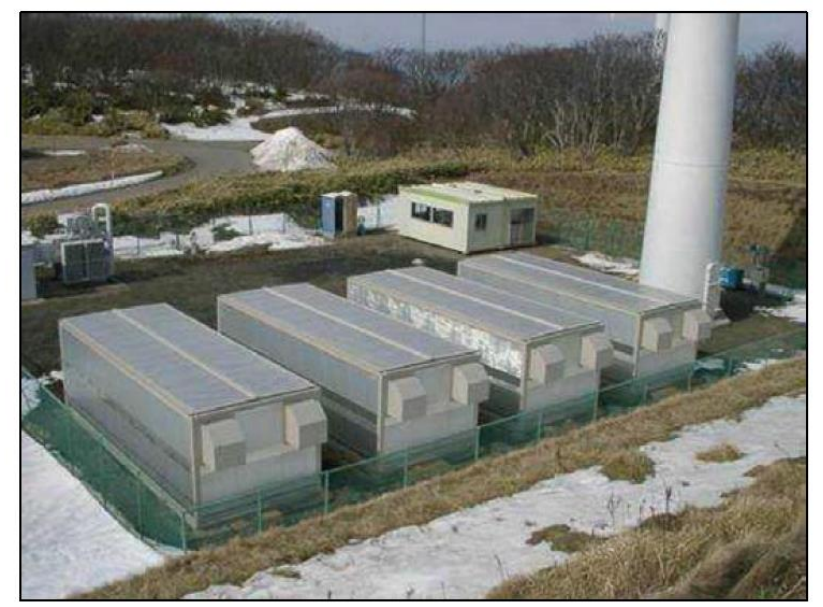

Figure 2.12: The Tappi Wind Park Advanced Lead-acid battery system (by Hitachi). Image taken from [Akhil, 2013]. 


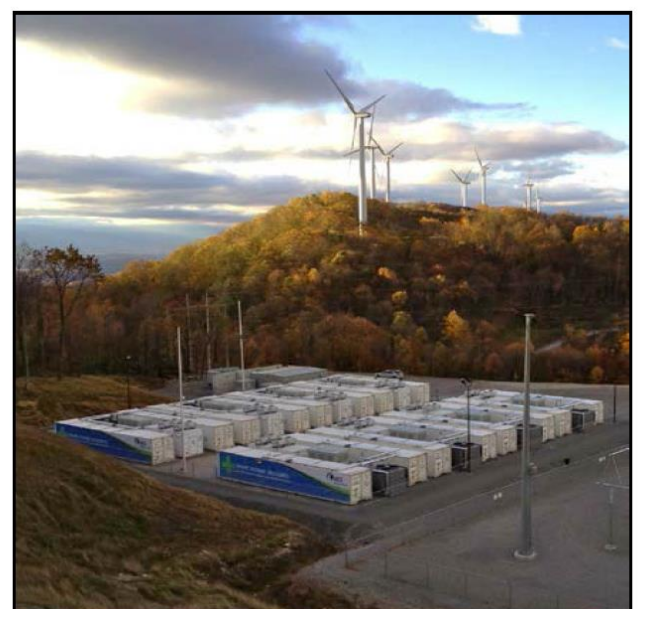

Figure 2.13: AES Storage LLC's Laurel Mountain Li-lon Energy Storage (32MW). Image taken [Akhil, 2013].

\subsection{Selection of Energy Storage Systems for HESS}

A HESS has been proposed in this work to provide energy in grid scale. Three types of energy storage systems have been considered for the proposed HESS: Battery, Flywheel, and Ultracapacitor/ Supercapacitor. The following table (Table 2.4) shows the comparison between Battery, Flywheel and Supercapacitor based on various parameters [BU, 2015]:

Table 2.4: Comparison between Battery, Flywheel, and Supercapacitor.

\begin{tabular}{|c|c|c|c|}
\hline Specifications & Battery & Flywheel & Supercapacitor \\
\hline $\begin{array}{l}\text { Typical discharge time } \\
\text { (runtime) }\end{array}$ & $5 \mathrm{~min}-8 \mathrm{hrs}$ & $1 \mathrm{sec}-1 \mathrm{~min}$ & $10 \mathrm{sec}-1 \mathrm{~min}$ \\
\hline Existence in history & Many decades & Many years & Few years \\
\hline $\begin{array}{l}\text { Temperature range for } \\
\text { operation }\end{array}$ & $\begin{array}{l}\text { Li-ion: charge }-0^{\circ} \mathrm{C} \text { to } \\
45^{\circ} \mathrm{C} \\
\text { Discharge- }-20^{\circ} \mathrm{C} \text { to } \\
60^{\circ} \mathrm{C} \text { [2] }\end{array}$ & $0^{\circ} \mathrm{C}$ to $40^{\circ} \mathrm{C}$ & $-40^{\circ} \mathrm{C}$ to $85^{\circ} \mathrm{C}$ \\
\hline Max Power range & Multiple megawatts & Multiple megawatts & Thousands of kilowatts \\
\hline Typical reliability & $\begin{array}{l}\text { Inversely proportional } \\
\text { to runtime }\end{array}$ & $\begin{array}{l}\text { Moderate (but higher for } \\
\text { newer technologies) }\end{array}$ & High \\
\hline Recharge time & $\begin{array}{l}10 \text { times of its } \\
\text { discharge time }\end{array}$ & Seconds/minutes & Seconds \\
\hline $\begin{array}{l}\text { Typical Number of full } \\
\text { discharge cycle }\end{array}$ & Up to 3000 & Unlimited & Up to 1 million \\
\hline
\end{tabular}


The roles of the selected storage systems in the proposed HESS in this work are described in the following paragraphs.

\section{Role of Flywheel in the Proposed HESS:}

The main role of Flywheel in the proposed HESS is to aid power generation curve smoothening and power quality improvement. Flywheel has been chosen to provide sharp power boost (very high power) in case of sudden increment in demand and will be charged again during the decrement of demand. It can supply for up to 15 minutes. The storage operator will have to pay for the energy according the rate at that time. Flywheel charges to store energy and operate as a load, during the supply it discharges to provide extra demand and operate as a generator. In practical scenario, a Flywheel means a system consists of a number of Flywheels units.

\section{Role of Supercapacitor in the Proposed HESS:}

Supercapacitor was also used to aid in power generation curve smoothening. Supercapacitor was chosen to supply the sharp increased demand as it can supply within seconds. However, it cannot provide very high power [Locker, 2005; Pegueroles-Queralt, 2015; Zhang, 2015; Zheng, 2015]. So, it can serve up to a certain power level. It is charged when demand is lower than generation and stores that energy. It supplies or discharges when demand is higher than generation. During charging it acts as a load and the operator needs to pay for that energy. When discharging it acts as a generator. In practical scenario, a supercapacitor means a system consists of a number of Supercapacitors.

The power data used in this work were available in 5 minute interval. Therefore, any power demand variations within 5 minute cannot be analyzed. However, both the Flywheel and Supercapacitor, and their control systems are designed to provide the power and energy requirement by the grid in very short duration and provide the required frequency regulation. Therefore, though Flywheel and Supercapacitor were chosen to aid power generation curve 
smoothening, both of these storage systems were assumed to satisfy very short duration frequency regulation.

\section{Role of Battery in the Proposed HESS:}

Battery has been chosen to serve the followings [Lian, 2014]:

1. Power generation curve smoothening - If sharp increment in power demand lasts for more than 10-15 minutes (hours), battery replaces the Flywheel systems.

2. If demand is higher than generation and the increment rate is low, battery supplies as a generator.

3. Basically battery supplies when the demand peak lasts for a longer period comparatively.

Lithium ion battery was used in the proposed HESS. Lithium-Ion (Li-ion) battery is providing the services [Matty 2005, Papic, 2014]. All the batteries are charged during the off peak hours when the energy cost is low.

\subsection{Chapter Summary}

In this chapter a comprehensive literature survey on various energy storage systems has been conducted. Li-Ion battery, Flywheel, and Supercapacitor received special focus as these elements were utilized in the proposed hybrid energy storage system (HESS) in this thesis. The working principles, classification, characteristics, specifications, and grid scale applications of these storage systems have been discussed. The current state of the technologies and their applicable roles in the proposed HESS of this work have been explained as well. 


\section{Chapter 3}

\section{PROPOSED MODEL AND FORMULATION}

\subsection{Introduction}

This chapter focuses on the development of formulation of the desired optimization problem with constraints for a hybrid energy storage system (HESS). The proposed HESS consists of a number of Li-ion battery systems, Flywheel systems, and Supercapacitor (Ultracapacitor) systems (Figure 3.1). The optimization problem considered all the operational constraints of these systems. The solution of this problem would be the optimized maximum operating power and energy of the selected storage systems. Each of these systems provides energy to the grid when required. Figure 3.1 represents the proposed model of the hybrid energy storage system (HESS).

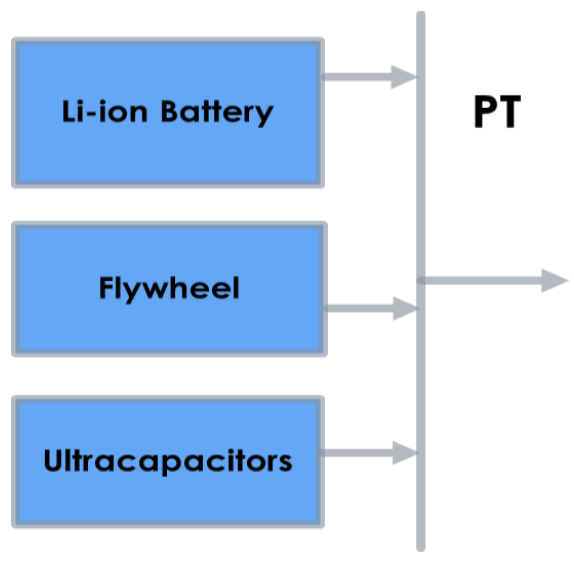

Figure 3.1: Proposed Hybrid Energy Storage System

\subsection{Nomenclature}

Definition of the terms used in the formulation:

$\begin{array}{ll}\text { Parameters } & \text { Definition } \\ A_{i j} & \text { Purchasing cost of a system ( } i^{\text {th }} \text { system of } j^{\text {th }} \text { type of storage system) } \\ B_{i j} & \text { Cost per KW power of a system } \\ C_{i j} & \text { Cost per KWH energy of a system } \\ \Delta t & \text { Time interval of power data } \\ \overline{P E_{i j}} & \text { Optimized maximum power output of a system (to be calculated) }\end{array}$




$\begin{array}{ll}\overline{E E_{i j}} & \text { Optimized maximum energy output of a system (to be calculated) } \\ N Y_{i j} & \text { Lifetime in years of each system } \\ N C_{i j} & \text { No. of charge/discharge cycles per year } \\ D O D_{i j} & \text { Rated depth of discharge of a system } \\ D O D_{i j, t} & \text { Depth of discharge of each system at any time } t \\ \overline{\overline{P E_{j}}} & \text { Maximum rated output power of a system } \\ \overline{\overline{E E_{j}}} & \text { Maximum rated output energy of a system } \\ \overline{P E R_{j}} & \text { Minimum ramp rate of each system of HESS } \\ \overline{P E R_{j}} & \text { Maximum ramp rate of each system of HESS } \\ N T & \text { Total number of time steps } \\ N E_{j} & \text { No. of each type of system }\end{array}$

\subsection{Objective Function and Constraints}

The objective function represents annualized capital cost of the proposed HESS, where the three terms are for fixed costs, power conversion costs and energy storage element costs:

$$
\text { Minimize: } \sum_{\substack{i=1 \\ j \rightarrow B, F, C}}^{N E}\left[\frac{A_{i j}+B_{i j} \cdot \overline{P E_{i j}}+C_{i j} \cdot \overline{E E_{i j}}}{N Y_{i j}}\right]
$$

The goal is to minimize the total asset cost of a hybrid energy storage system by optimizing the maximum supply power and maximum supply energy of each system of the energy storage system. The objective function was subjected to a number of constraints.

At any time $t$, sum of the output power of all 'ON' systems of HESS is equal to the total power required from HESS at that time. HESS was designed to provide a certain amount of power to the grid according to the change in demand. At a particular time $t$, the amount of required power determines the type of system and the number of that type of system to discharge energy.

$$
\sum_{i=1, j \in\{B, F, C\}}^{N E} P E_{i j, t}=P T_{t} \quad \forall t
$$

Equation (3.3) and (3.4) limited the output power of a system for all time $t$. At any time $t$, the output power generated by a system of HESS should be within a limit, which is defined by the achieved optimized maximum output power from the solution of the optimization formulation. 
Also, the optimized maximum power of a system should be less than (or equal to) the rated power of that used storage system.

$$
\begin{array}{ll}
P E_{i j, t} \leq \overline{P E_{i j}} & \forall t, i, j \\
\overline{P E_{i j}} \leq \overline{\overline{P E_{j}}} & \forall i, j
\end{array}
$$

Equation (3.5) and (3.6) limited the output energy of a system for all time $t$. In the same way, at any time $t$, the output energy of a system of HESS should be within the limit defined by the achieved optimized maximum energy from the solution of the optimization formulation. Also, the optimized maximum energy of a system should be less than (or equal to) rated energy of that used system.

$$
\begin{array}{ll}
E E_{i j, t} \leq \overline{E E_{i j}} & \forall i, j, t \\
\overline{E E_{i j}} \leq \overline{\overline{E E_{j}}} & \forall i, j
\end{array}
$$

Output energy of a system of HESS at any time, $t$, is determined by the summation of energy of that system at time, $t-1$, and the product of output power at time $t$ and time difference between two consecutive time steps.

$$
E E_{i j, t}=E E_{i j, t-1}+P E_{i j, t} \cdot \Delta t \quad \forall t
$$

The ramp rate of a system of HESS limited the output power in any time interval. The power provided by a system during a time interval should remain within the limit defined by the minimum and maximum ramp rate of that system.

$$
\underline{P E R_{j}} \leq P E_{i j, t}-P E_{i j, t-1} \leq \overline{P E R_{j}}
$$

Depth of discharge of a system at time, $t\left(D O D_{i j, t}\right)$ is determined by dividing the amount of energy used at time $t$ by the optimum energy of that system. It is expressed in percentage. According to the definition of the rated depth of discharge $\left(D O D_{i j}\right)$, it is the allowed maximum amount of energy to be discharged by the storing system expressed as percentage of the maximum energy capacity of that system. For energy storage system (especially battery systems) the manufacturer generally does not recommend the full amount of energy to be discharged of the rated capacity 
(i.e., $100 \% D O D$ ). However, an optimum maximum amount of allowed energy discharged (i.e., rated $D O D$ or $D O D_{i j}$ ) can achieve prolonged lifetime for the storage system.

$$
D O D_{i j, t}=\frac{E E_{i j, t}}{\overline{E E_{l \jmath}}} \cdot 100 \%
$$

Depth of discharge of a system at any time $t$ is limited by the rated depth of discharge of that system $D O D_{i j}$. At any time $t$, the discharge of a system cannot be more than the rated depth of discharge.

$$
D O D_{i j, t} \leq D O D_{i j} \quad \forall t
$$

Number of cycle is define by Equation 3.11, where, $N T$ is the total number of time steps. For every time step, change in power of a system of HESS is monitored, converted to energy and summed. This change can be either positive (charging) or negative (discharging). The absolute value ignores the negative signs and sums up all the changes. Summation of one full charging and full discharging values (ignoring the negative signs) indicate one cycle. When the total value (after summation at the end of time, $N T$ ) is divided by the optimum energy output, total number of cycle of that system is determined.

$$
N C_{i j}=\frac{\sum_{t=1}^{N T}\left|P E_{i j, t}\right| \cdot \Delta t}{2 \cdot \overline{E E_{\imath \jmath}}}
$$

The cycle life constant value is different for different types of systems. Equation 3.12 determines the number of year of a system. For a given rated depth of discharge of a system, the calculate $N C_{i j}$ from Equation 3.11 and given constant value for that system (can be calculated from the system's manufacturer datasheet), the total number of operation year of a system ( $\left.N Y_{i j}\right)$ can be calculated from Equation 3.12.

$$
D O D_{i j} \cdot N C_{i j} \cdot N Y_{i j}=\text { constant }
$$

Equations (3.11) to (3.12) poses a nonlinear optimization challenge. It can be solved to determine optimal sizes of the component in energy storage systems that together comprise the HESS possessing requisite characteristics. 


\subsection{Chapter Summary}

This chapter presented the objective function and the related constraints of an optimization problem for a proposed hybrid energy storage system (HESS). The objection function was to minimize the total asset cost per year of the proposed HESS by optimizing the maximum operation power and energy of all the storage systems. This function also included some independent cost parameters, such as capital, power, and energy cost. The subjected constraints were related to the specifications of the selected type of storage systems, such as rated power capacity, rated energy capacity, rated and allowed depth of

discharge (DOD), ramp rate, number of life cycle at rated DOD. The systems were also required to satisfy the additional power and energy required by the grid at any time. 


\section{Chapter 4}

\section{ANALYSES AND RESULTS}

\subsection{Introduction}

This chapter presents the key results of the optimization problem solutions solving the formulation stated in Chapter 3, optimized results for a set of values of the selected HESS for two types of power demand dataset cases: Data Case 1 and Data Case 2. In Data Case 1, one-day Ontario power demand data were used and in the Data Case 2 power demand data were created with various magnitude of power demand fluctuation for slow and fast demand change cycles. Results from the analyses of both data cases are included and discussed in this chapter.

\subsection{Selection of MATLAB Solvers: 'Fmincon', 'Patternsearch' and 'Genetic Algorithm'}

Three optimization tools 'Fmincon', 'Patternsearch' and 'Genetic Algorithm' in MATLAB have been utilized to determine the optimum solution of the optimization problem.

a. Genetic Algorithm: Genetic Algorithm (GA) is a search method that follows biological evolution process to solve any type of optimization problem. It creates initial set of values for the parameters to be optimized, if not given. After each iteration (generation), it generates a set of values (population) of the variables (individuals) depending on the population in the previous generation. The best value among those act as parents to generate next set of values and this continues till the optimum solution is achieved based on the solver stopping criteria.

b. Fmincon: This is a gradient based method of local minima determination. Identification of a local minimum position completely depends on the start point or the initial point of the optimization parameters. Based on the location of the initial point, 'fmincon' provides the nearest local minimum as a solution when the gradient changes sign.

c. Patternsearch: This is a direct search method (a type of global search method) utilizing polling of a number of points based on the initial or start point. The solver gradually refine the mesh and perform more polling taking the lowest result of the previous 
iteration as new start point. The complete polling method and gradual refinement of the mesh leads the solution to the global minimum or a minimum close to the global minimum point for the start point at any location.

Fmincon and Genetic Algorithm provided better solutions and Patternsearch did not provide satisfactory solution. For Data Case 1 analysis (Section 4.3) results from Genetic Algorithm solver are presented. For Data Case 2 analysis (Section 4.4) results from Fmincon solver are presented.

\subsection{Optimization Problem Solution with Real Power Demand Data: Data Case 1}

\subsubsection{Algorithm for Data Case 1}

The following steps summarize the analysis of power data and solution of the optimization problem approach:

1. One-day 5 minute interval Power Demand Data was scaled to $1 / 50^{\text {th }}$.

2. A reference power curve was established with least-square best-fit line.

3. Standard deviation of the power data, frequency of power demand change, and power flow of HSS were calculated.

4. Initial power values $\left(P E_{\max }\right)$ were selected for each system based on maximum power required, and initial values of each system for other optimization variables were calculated based on different basic data (A, B, and C cost; Rated power, Rated energy, and DOD; and Cycle Life) and constraints: maximum energy $\left(E E_{\max }\right)$, power at each time $\left(P_{t}\right)$, energy at each time $\left(E_{t}\right)$, DOD at each time $\left(D O D_{t}\right)$, number of cycle per year $(N C)$, and number of year $(N Y)$.

5. Options for Genetic Algorithm were set and the solver was run.

6. Optimized output were processed and results for optimized power (PEmax), energy (EEmax), and Total cost per year were identified. 


\subsubsection{Power Demand Data for Data Case 1}

One-day Ontario power demand data obtained from the Independent Electricity System Operator (IESO) website was used in this research project. The actual power demand data at fiveminute interval, as shown in Fig. 4.1 (red line), were utilized. To determine the distribution of power supplied by each type of storage systems, a reference power curve was necessary, where the reference power curve was assumed to represent the total power that would be provided by the main generators of the power system (i.e., the power generation curve). When the actual power demand is greater than the reference curve, the required power is supplied by one or a combination of the systems of the HESS (discharging), and when the actual power demand is lower than the reference curve, the additional power is supplied to one or a combination of the systems of the HESS (charging). For each hour, a best-fit straight line was drawn through the actual power demand data using the least square curve fitting method. This facilitated the charging and discharging energies of the HESS elements to be equal for each hour. This best-fit line was considered as the reference power curve (Fig. 4.1 dotted black line). When the main generators of a power system follow the reference power curve with the best-fit straight line through the actual power demand curve, the power curve to be supplied by the main generators gets smoothened significantly.

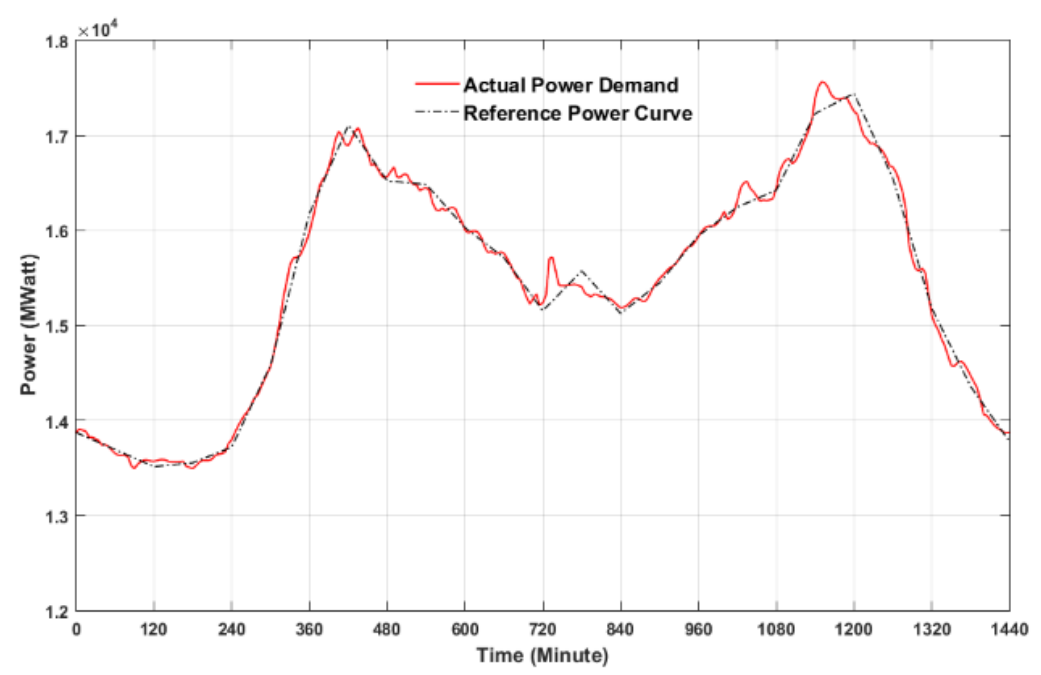

Fig. 4.1. Actual Power Demand Curve and the Reference Power Curve. 
One important issue to be recognized in power system is the variation of power demand in very short period of time. The actual power demand can be increased significantly for duration less than five minutes. In the power demand analysis for this project, the actual power demand data were available at five-minute interval. Therefore, the variations in actual power demand in less than five-minute are not captured in the data and cannot be analyzed. However, it should be noted that the purpose of using Flywheels and Ultracapacitors is to satisfy very short duration power demand fluctuations. These energy storage systems are designed and controlled to take care of such short duration variations inherently. Any power demand variations for more than five-minute period were analyzed in this work. In the Ontario power demand data, utilized in this work, for the power demand variations very large amount of energy would be required and consequently, very large number of storage systems would be required. In this work the power data were scaled down by 50 times, as if the power system was supplying one-fiftieth $\left(1 / 50^{\text {th }}\right)$ of the Ontario Power system. From this point forward, the power demand data are scaled down to one-fiftieth times of the original data for convenience. Nevertheless, the proposed HESS and method would be able to supply for the full Ontario power system or other large scale systems. When the smoothened power curve was subtracted from the actual power demand curve a numerous peaks were found (Fig. 4.2). These power demand peaks were supplied by Li-ion batteries, Flywheels, and Ultracapacitors and the power distribution was determined by the optimization algorithm solver.

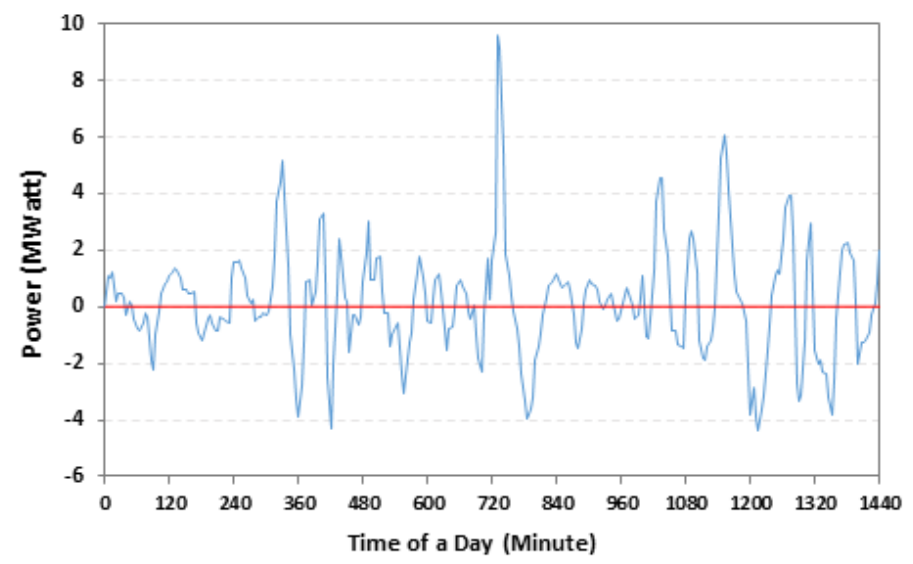

Fig. 4.2. Power Flow From and To HESS. Power Demand Data was scaled to $1 / 50^{\text {th }}$. Peaks above the Red Line is for HESS Discharging and the Peaks below are for HESS Charging. 
From Fig. 4.2, it is clear that during some hours the magnitude of the peaks are significantly high. The scaled power demand data was analyzed to determine standard deviation in each hour of the day. The power demand peaks in Fig. 4.2 were also analyzed to determine the frequency of demand change (i.e., power data changing sign) in each hour. During the $10^{\text {th }}$ and $13^{\text {th }}$ hour the frequencies were 5 and 2, respectively. For rest of the hours, the change in power demand sign was only once per hour. The optimization problem was solved using power demand data of an hour. The power data were utilized for the optimization to determine the effects of change in standard deviation and frequency of demand change. Basic data of different HESS elements were obtained from manuals and literature, where the storage systems were utilized in grid scale. Table 4.1 shows datasheet for Li-Ion Batteries, Flywheels and Ultracapacitors. The optimization problem was solved using program scripts written in MATLAB 2015.

Table 4.1: Parameters for Li-ion Battery, Flywheel, and Ultracapacitor

\begin{tabular}{|l|l|c|c|c||}
\hline \hline Parameters & Unit & Li-ion Battery & Flywheel & Ultracapacitor \\
\hline System Capacity - Net & & & & \\
\hline Hours of Energy Storage at Rated Capacity & Hrs & 30,000 & 20,000 & 300 \\
\hline Depth of Discharge (DOD) per Cycle & $\%$ & 1 & 0.25 & 0.17 \\
\hline Energy Capacity @ Rated DOD & $\mathrm{kWh}$ & 99 & 99.9 & 99 \\
\hline Energy Capacity @ 100\% DOD & $\mathrm{kWh}$ & 30,000 & 5,000 & 50 \\
\hline Number of Cycles per Year & $\mathrm{cycle} /$ year & 4000 & 5,000 & 51 \\
\hline Plant Life & Year & 15 & 15,000 & 25,000 \\
\hline Plant Cost & & & & 25 \\
\hline Power (B_cost) & $\$ / \mathrm{kW}$ & 514 & 867 & 1,994 \\
\hline Storage- @ Rated DOD (C_cost) & $\$ / \mathrm{kWh}$ & 874 & 5,168 & 3,685 \\
\hline Total Plant Cost (TPC) (A_cost) & $\$ /$ system & $41,642,000$ & $43,189,100$ & 782,450 \\
\hline
\end{tabular}

\subsubsection{Effects of Different Parameters for Data Case 1}

\section{A. Effects of Number of Type of Storage Systems and Number of System of Each Type}

The $1 / 50^{\text {th }}$ scaled power demand data of the $11^{\text {th }}$ hour was used in both solvers to determine the effects of number of type of system (NT) and number of system of each type (ND) on the total cost per year. Fig. 4.3 presents the results and it shows that the total cost was increased with 
increased number of system in each type. However, the total cost decreased with increased number of type of system, when with $N T=1$ only Battery was used, with $N T=2$ Battery and Flywheel were used and with $N T=3$ all three types were used. Among the types of systems, inclusion of Battery contributed to the total cost significantly. The observations shows that increasing number of systems of each types does not help lower the total cost; rather increases the cost. For $N D=2$ and $N D=3$, the cost decreased for increased $N T$ (i.e., combination of energy storage systems helped lowering the total cost than using one type of system). However, for ND $=1$ and $N T=2$, the cost was lowest indicating that for the selected power data one Battery and one Flywheel system together would be most economical.

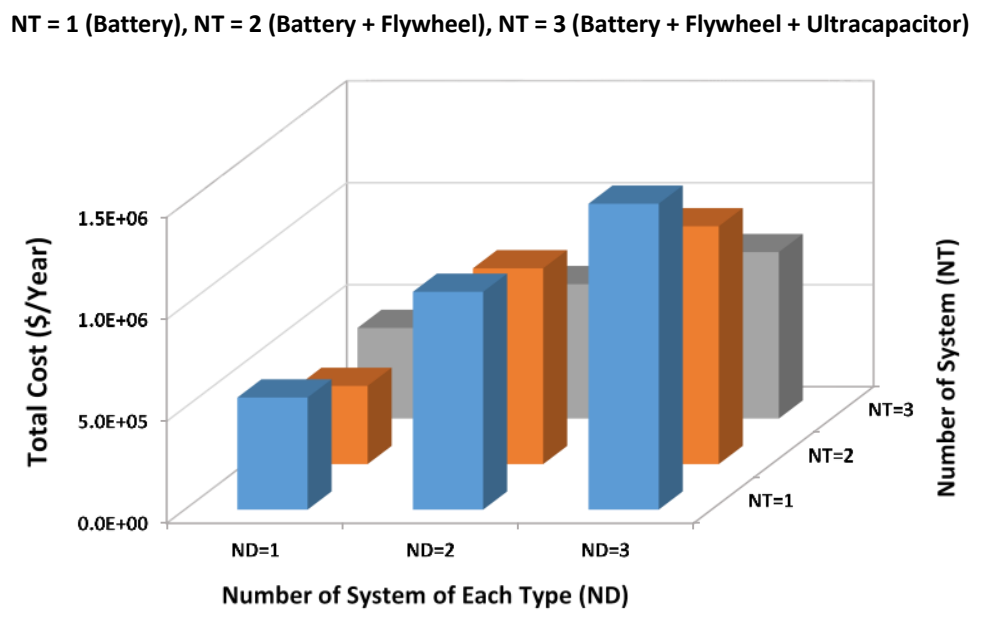

Fig. 4.3. Change in Total Cost per Year with Increased Number of System for Each Type (ND) as well as Increased Number of System Types (NT). (Power Data was of the $11^{\text {th }}$ Hour and Scaled to $1 / 50^{\text {th }}$ ).

\section{B. Effects of Power Demand Standard Deviation and Frequency of Demand Change}

Since the optimization problem was solved for one hour power demand data, it was essential to determine the effects of deviation of power demand and frequency of power demand change in an hour during a day. Power data for four different hours was utilized representing increasing standard deviation (SD). Fig. 4.4 shows the change in total cost per year, and optimum maximum power and optimum energy of Battery, Flywheel, and Ultracapacitor for the different standard deviation in power data. In these cases the number of each type storage system was one (ND = 1). The total cost per year generally increased with the increased SD. The optimum maximum 
power and maximum energy of all three types of storage systems increased with increased SD, except the optimized power was lowest for SD of 1.94 .
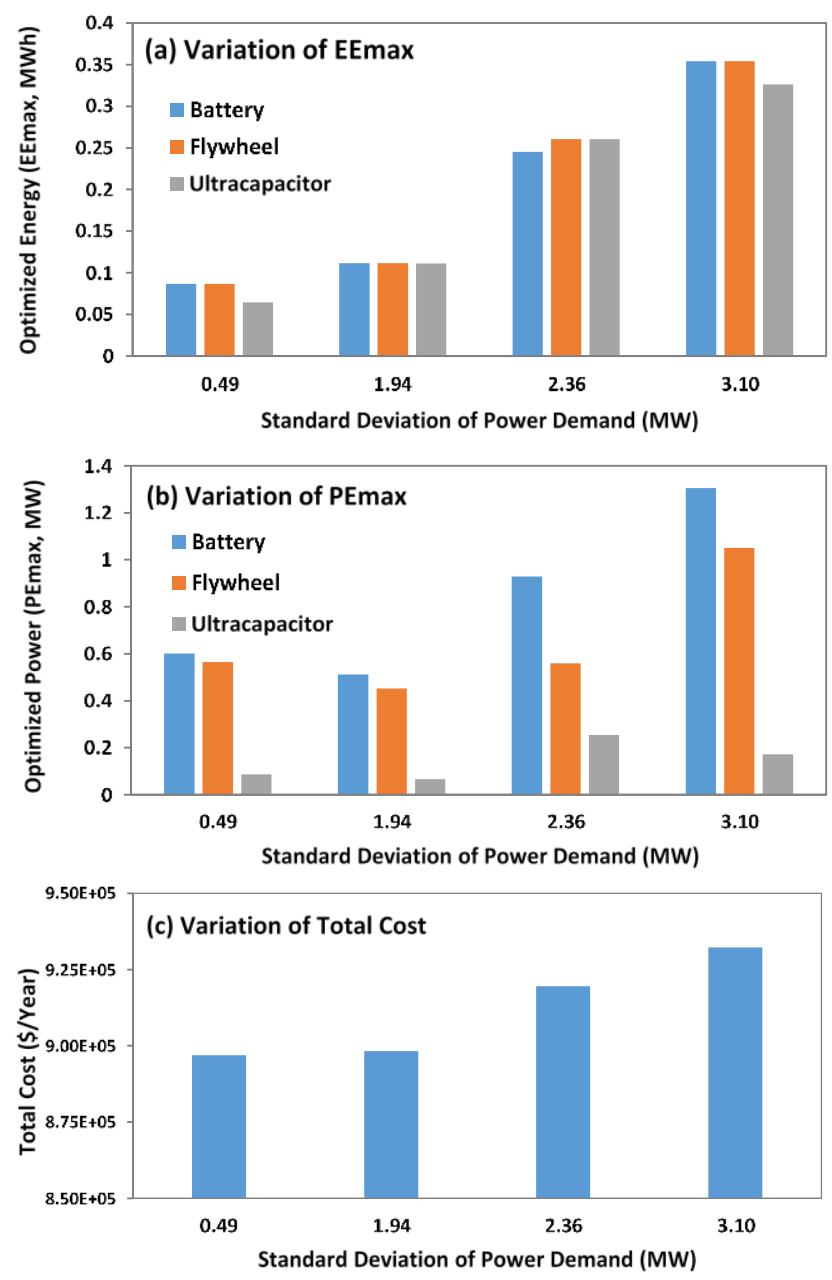

Fig. 4.4. Variation in (a) Optimum Energy $\left(E E_{\max }\right)$, (b) Optimum Power $\left(P E_{\max }\right)$ of Battery, Flywheel, and Ultracapacitor, and (c) Total Cost per Year with the Change in Standard Deviation of Power Demand Data. The Power Demand Data is Scaled to $1 / 50^{\text {th }}$ and Number of System for Each Type was $1(N D=1)$.

Fig. 4.5 shows the change in total cost per year, and optimum power and optimum energy of Battery, Flywheel, and Ultracapacitor for three different frequencies of power demand change (change in sign per hour). The number of each type storage system was one (ND =1). With higher frequency of power demand change, the total cost per year, optimum maximum power and maximum energy of all three types of storage systems decreased. This could be due the fact that 
with higher frequency of power demand change, the demand peaks to be supplied by HESS were smaller in magnitude, and all three types of systems had opportunity to be charged and discharged more than once. This indicates that the proposed HESS would be more effective for the higher fluctuating power demand with lower magnitude of changes.
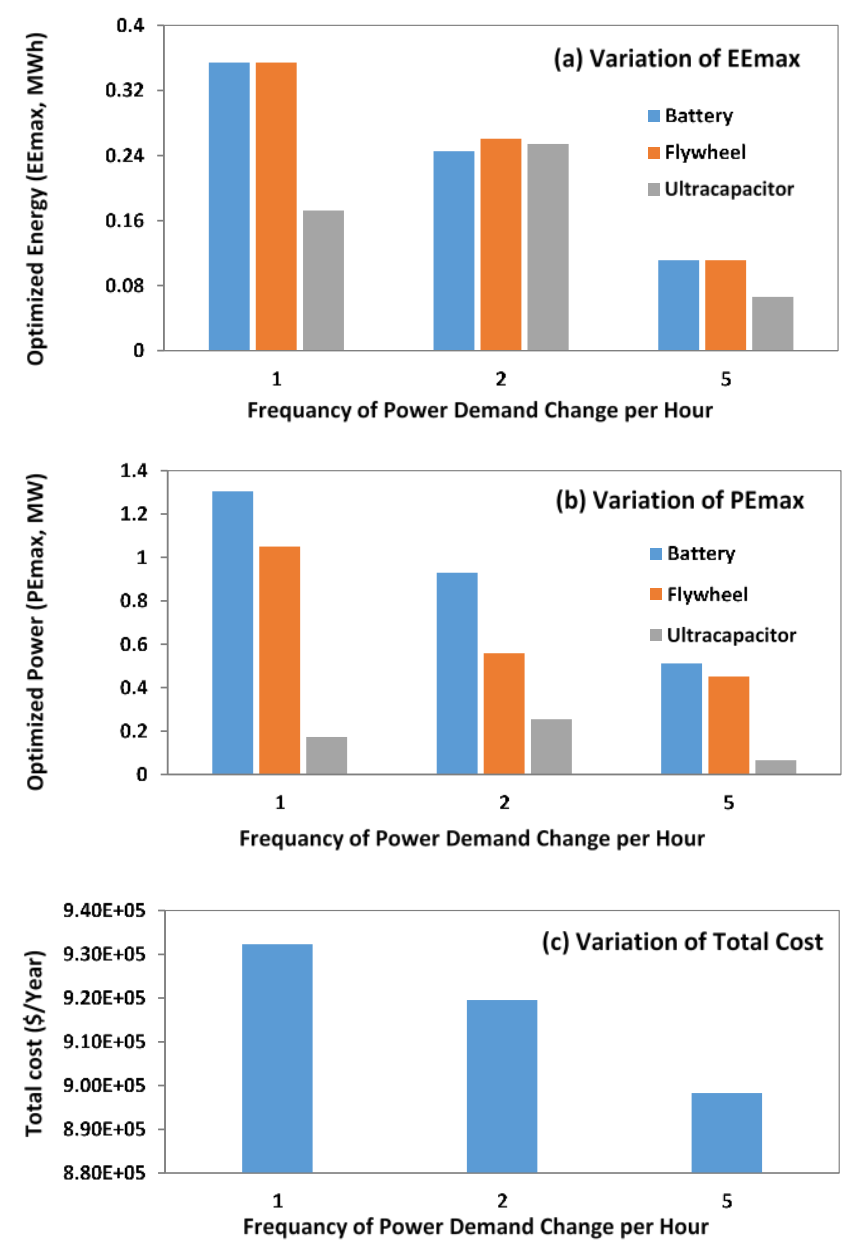

Fig. 4.5. Variation in (a) Optimum Energy (EEmax), (b) Optimum Power (PEmax) of Battery, Flywheel, and Ultracapacitor, and (c) Total Cost per Year with the Change in Frequency of Power Demand per Hour. The Power Demand Data is Scaled to $1 / 50^{\text {th }}$ and Number of System for Each Type was $1(N D=1)$.

\section{Effects of Cycle Life Constant and Rated Power}

The $1 / 50^{\text {th }}$ scaled power demand data of the $11^{\text {th }}$ hour was used to determine the effects of change in Cycle Life constant of Flywheel and Battery on the total cost per year. Fig. 4.6 presents 
the results of change in total cost with the change in Flywheel ( $F_{-}$Const) and Battery constant (B_Const) for 1x and 3x Rated Power of Flywheel and Battery. From Fig. 4.6 several observations can be made. In most of the cases of cycle life constant the total cost per year obtained were higher for 1x Rated Power of Battery and Flywheel compared to the 3x Rated Power cases. Higher F_Const and B_Const both contributed to lower total cost per year, which is beneficial with respect to HESS since the storage system replacement time will be longer.
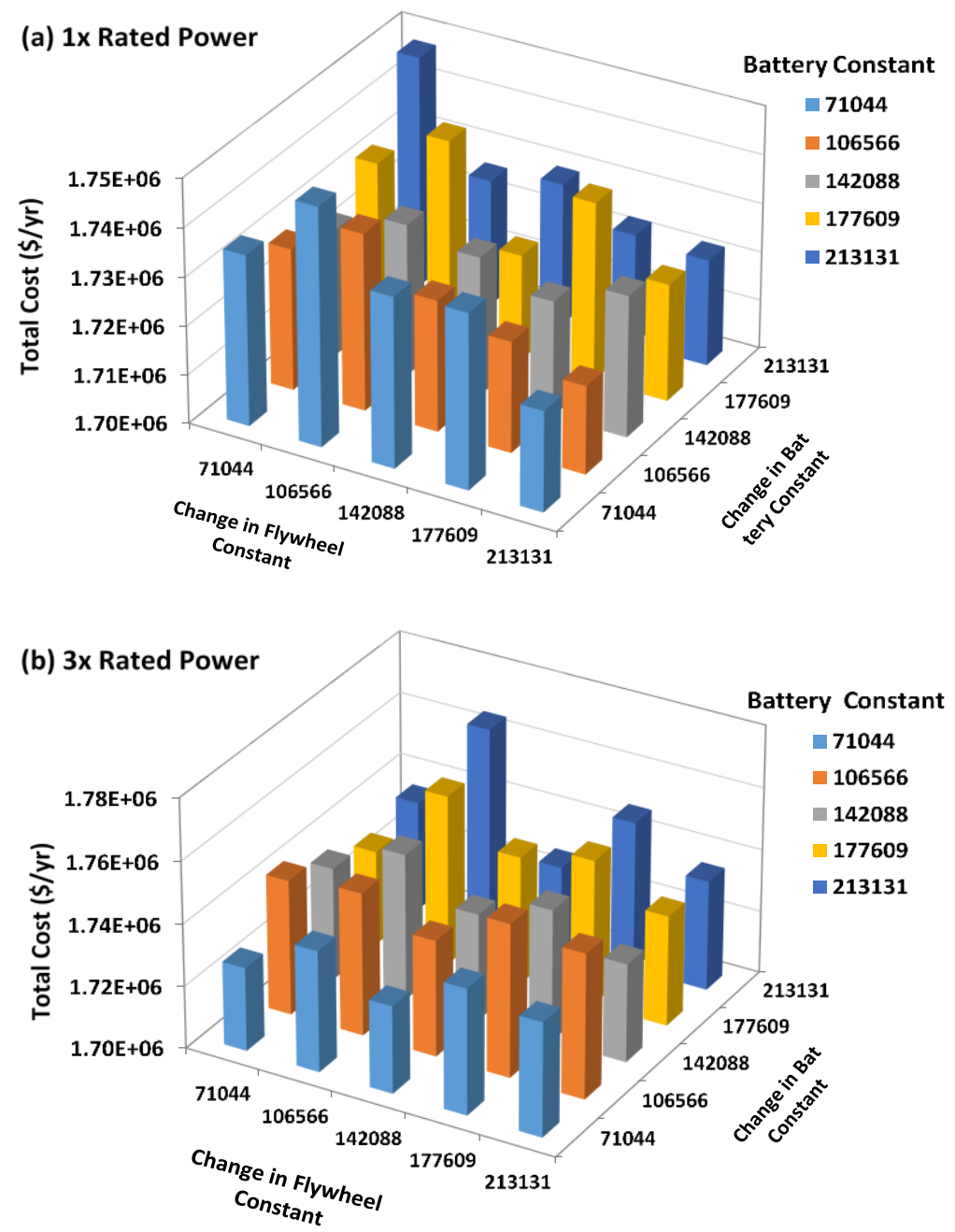

Fig. 4.6. Change in Total Cost with Change in Flywheel Constant and Battery Constant for: (a) 1x Rated

Power of Battery and Flywheel and (b) 3x Rated Power of Battery and Flywheel. Constant Value of 142088 is the Average of Battery and Flywheel Constants. Number of System for Each Type is $2(N D=2)$ and Power Data was of the $11^{\text {th }}$ Hour. 
Fig. 4.7 shows the change in total cost with change in Constant for both $1 x$ and $3 x$ Rated Power. In these cases the constant values of Battery and Flywheel were kept same and these values varied at the same time. When the constant values of two types of systems are kept same, they behave as a single type of systems, except their cost parameters. This was done so that the effects of increment of constant can be identified. However, no defined trend was found. For 1x Rated Power highest constant resulted lowest cost; whereas, in 3x Rated Power lowest constant resulted the lowest cost.

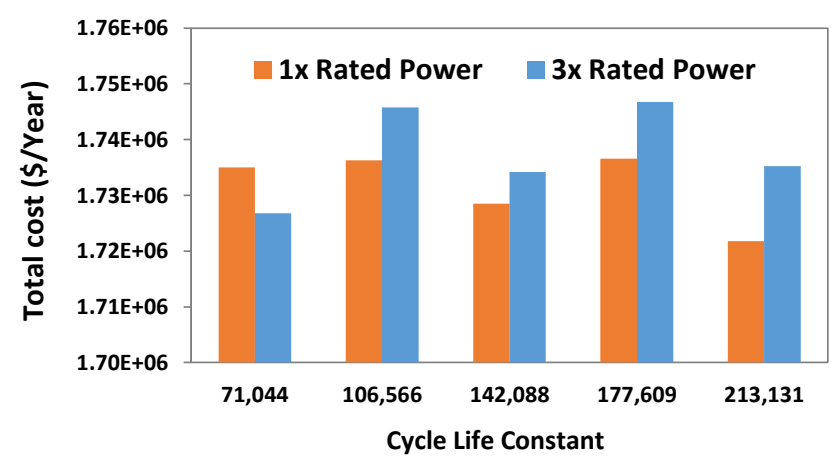

Fig. 4.7. Change in Total Cost per Year with Change in Constant (Keeping Battery Constant and Flywheel Constant Same for Each Case) for 1x (orange bars) and 3x (blue bars) of the Rated Power of Battery and Flywheel. Number of System for Each Type is $2(N D=2)$ and Power Data was of the $11^{\text {th }}$ Hour.

\section{Scalability of the Proposed HESS}

The power demand data were also used with scaling down to $1 / 10^{\text {th }}$ and $1 / 20^{\text {th }}$ to determine the optimized results and compare to the results of $1 / 50^{\text {th }}$ scaled down power data. This was done to identify the power data scaling down effects on the cost and maximum power and energy results. The results comparing these two power data scaling approaches are shown in Table 4.2. The optimum maximum power and maximum energy decreased linearly with decreased power demand data (increased scaling down). However, the decrement of the total cost was not linear with the decreased power demand data. The decrement in cost became lower for increased scaling $\left(1 / 50^{\text {th }}\right)$. This indicates that the selected HESS is scalable and more economical for higher power demand system. 
Table 4.2: Optimized Results with Power Demand Data Scaling

\begin{tabular}{|l|c|c|c||}
\hline Parameters & $\begin{array}{c}\text { Power Data } \\
\text { Scaling }=\mathbf{1 / 1 0 ^ { \text { th } }}\end{array}$ & $\begin{array}{c}\text { Power Data } \\
\text { Scaling }=\mathbf{1 / 2 0 ^ { \text { th } }}\end{array}$ & $\begin{array}{c}\text { Power Data } \\
\text { Scaling }=\mathbf{1 / 5 0 ^ { \text { th } }}\end{array}$ \\
\hline PEmax (MW) & 3.671 & 1.813 & 0.735 \\
\hline EEmax (MW-h) & 0.7338 & 0.3448 & 0.147 \\
\hline Total Cost per & 1010500 & 935870 & 906460 \\
\hline
\end{tabular}

* NT = 3, ND = 1, Data $=11^{\text {th }}$ Hour, 1x Rated Power.

\subsection{Optimization Problem Solution for Power Demand Data Created with Different Magnitude of Demand Fluctuations: Data Case 2}

Fluctuation in power demand is unpredictable and the change can be slow or fast. In this study two types of power demand changes were considered: slow, where the power demand changes every 6 hours, and fast, where the demand changes in every 15 minutes. For 12 hours of operation there were 24 cycles of fast demand changes and 1 cycle of slow demand change. In addition, for both fast and slow cycle of power demand change different magnitudes of power demand were considered. It should be noted that Flywheels and Ultracapacitors in HESS have the capacity to satisfy fast cycles power demand fluctuations and Battery has the capacity to satisfy slow cycle changes. However, in the optimization problem solution, Battery can also provide energy for the fast cycle changes if necessary.

\subsubsection{Power Demand Data for Data Case 2}

Fig 4.8 presents four example Cases of power flow data of HESS with different magnitudes of slow and fast demand changes. These power demand data and other cases of power demand data were utilized in the analysis to observe the effect on life cycle of energy storage systems and the total cost per year. In Fig. 4.8, Case A represents a scenario, where the change in power demand of slow cycle is zero $\mathrm{MW}$ and the change in demand of fast cycle is $150 \mathrm{MW}$, and it is denoted as (0/150). For Case B the change in power demand of slow cycle is $50 \mathrm{MW}$ and the change in demand of fast cycle is $100 \mathrm{MW}$ and it is denoted as (50/100). Similarly, Case C is denoted as (100/50) and Case $D$ is denoted as (150/0). 

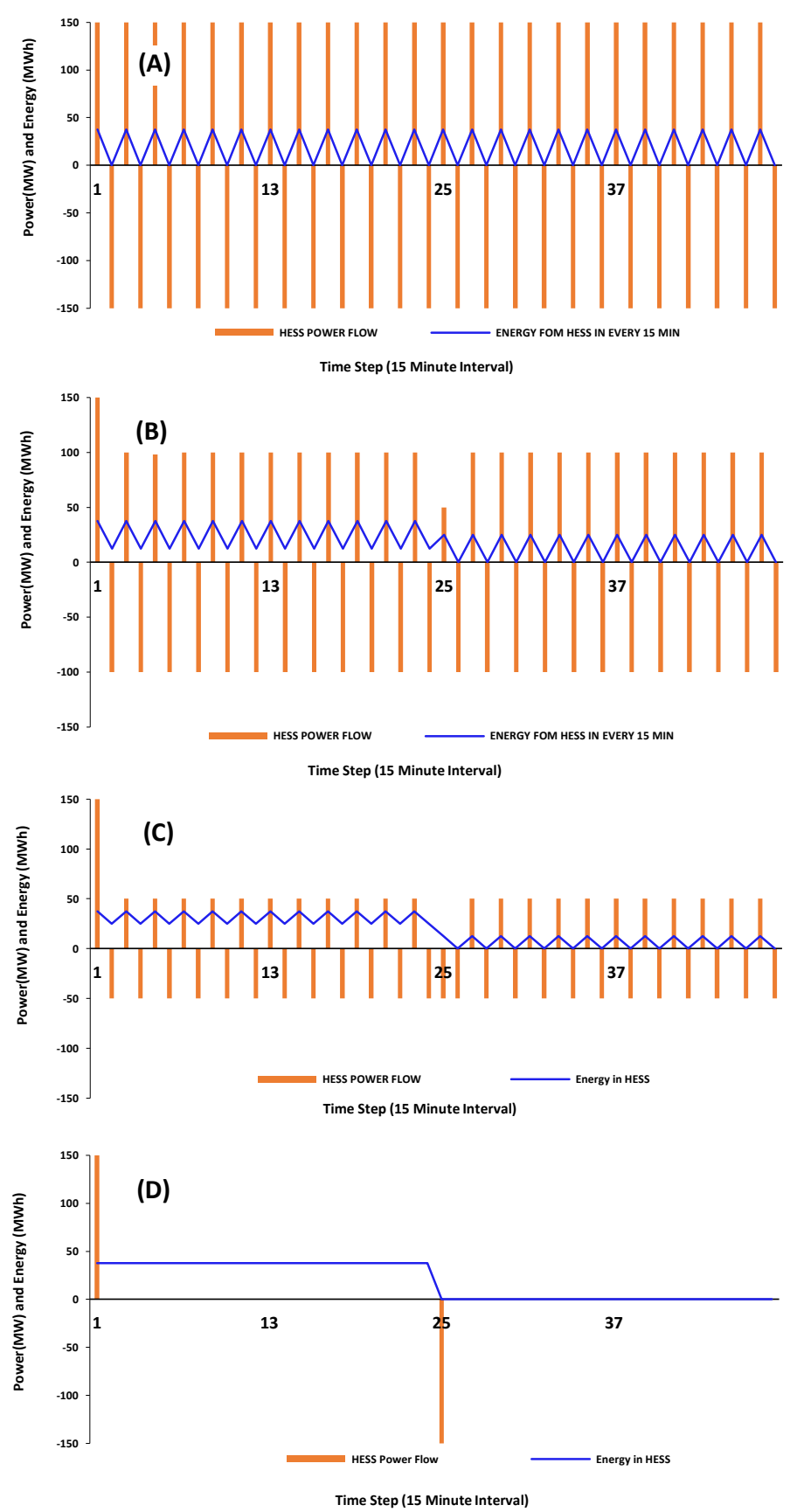

Fig. 4.8. Four Cases of Power Flow Data of HESS (Red bars) and Energy of HESS in Each Time Step of 15 Minutes (Blue line): Case: A (0/150), Case: B (50/100), Case: C (100/50) and Case: D (150/0).

One of the most important characteristic parameter of an energy storage system is its Cycle Life (which is a constant for the given rated depth of discharge). The Cycle Life constants of Battery, 
Flywheels, and Ultracapacitors considered in this study were 1000, 15000, and 42000, respectively. Flywheels and Ultracapacitors have relatively very high Cycle Life and Batteries have relatively lower Cycle Life. In the optimization solution, the total cost per year was optimized by increasing the life time (NY) systems of HESS, and that was achieved by decreasing the operation depth of discharge $(D O D)$ and the number of cycles per year $(N C)$. Both of these parameters can be decreased by increasing the maximum operation energy of each system of HESS. For each type of systems the maximum life time was considered to be 15 years.

\subsubsection{Algorithm for Data Case 2}

The following steps summarize solution of the optimization problem approach:

1. Power data for slow cycle and fast cycle were created.

2. Power data to be supplied by HESS was read from an excel file.

3. Number of type (NT) of energy storage system for the HESS and number of devices (ND) in each system were selected based on case to be analyzed.

4. Basic data were read ( $A, B$, and C cost, Ramp rate, Cycle life constant of each type of energy storage system).

5. Initial maximum operation power values (PEmax) were determined from input power data for each system and initial values for other optimization variables of each system were calculated using Equations in optimization problem.

6. Options for Fmincon were set and the solver was run.

Optimized output were processed and results for optimized total cost per year, power (PEmax), energy (EEmax), Depth of discharge (DOD) of each system, number of cycle per year $(N C)$ and number of year $(N Y)$ of each system were determined.

\subsubsection{Effects of Different Parameters: Data Case 2}

A. Effects of Number of Type of Storage Systems and Number of System of Each Type 
The optimization problem was solved for four types of HESS: (1) NT= 3 system, where the system consists of Flywheel, Battery and Ultracapacitor, (2) NT= 2 system, where the system consists of Flywheel and Battery, (3) NT= 1 system, where the system consists of Flywheel, and (4) NT= 1 system, where the system consists of Battery. Fig. 4.9 presents the optimized total cost per year for different ratios of power demand change of slow cycles and fast cycles for four types of HESS with the number of each type of system (ND) of 1.

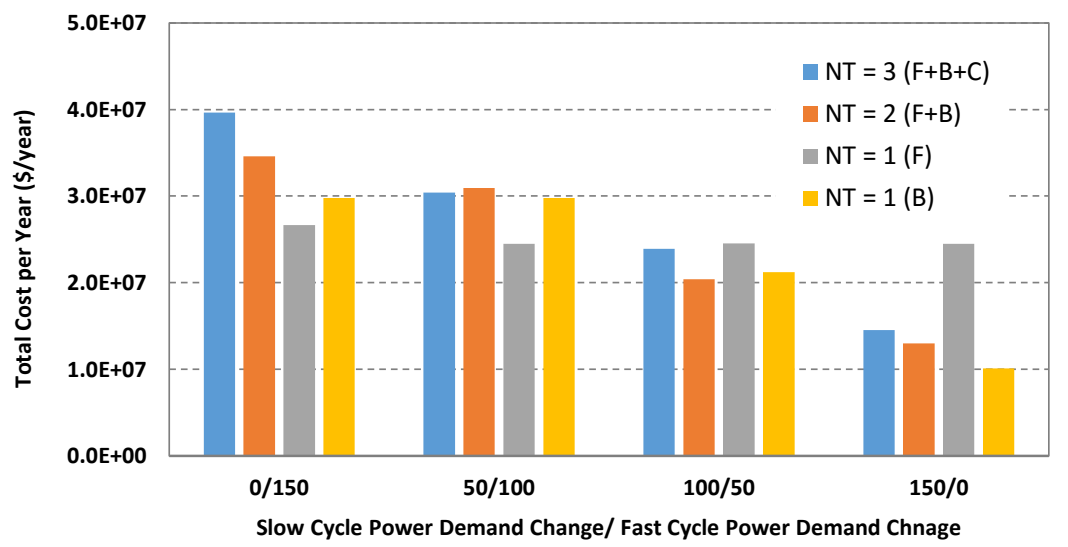

Fig. 4.9. Change in Total Cost per Year for Different Ratios of Power Demand Change in Slow Cycles and Fast Cycles for Number of Type of Systems, $N T=3(\mathrm{~F}+\mathrm{B}+\mathrm{C}$, Flywheel + Battery + Ultracapacitor; Red bars), $N T=2$ (F+B, Flywheel + Battery; Blue bars), $N T=1$ (F, Flywheel; Blue bars), and $N T=1$ (B, Battery; Blue bars) (Number of Each Type of System, $N D=1$ ).

Fig. 4.9 indicates that for power demand change ratio of 100/50 (ratio of demand change in slow cycles and fast cycles), $N T=2$ with Flywheel and Battery system resulted the lowest total cost per year. In addition, the system with Flywheel, Battery, and Ultracapacitor $(N T=3)$ resulted lower cost than the system with Flywheel only $(N T=1)$. Therefore, for certain power demand fluctuations, HESS with more types of systems can be beneficial as the cost becomes lower.

Fig. 4.10 presents the optimized total cost per year for different ratios of power demand change of slow cycles and fast cycles for number of type of systems (NT) of 2 and 3 and Number of each type of system (ND) of 1 and 2. For each case of power demand change ratio, the total cost is higher for number of each type of system, $N D=2$ (comparing figure (a) and (b)). For increasing 
power demand change in slow cycles and decreasing demand change in fast cycles, total cost per year decreases for both NTs and both NDs (except $N T=3$ system at 25/125 case with). This implies that if the magnitude of power demand fluctuations is high at fast cycle the cost increases due to higher energy is being supplied by low energy density systems, Flywheels and Ultracapacitors. While, the magnitude of demand change in slow cycle is high the cost decreases. For the power demand change ratios of 25/125, 50/100, and 75/75 the total cost is lower when the number of type of systems, $N T=3$ (Flywheel + Battery + Ultracapacitors) compared to $N T=$ 2 (Flywheel + Battery). In these cases inclusion of ultracapacitor helps lower the total cost as the fast power demand changes are satisfied by both Flywheels and Ultracapacitors. These observations justifies the use of HESS and inclusion of Ultracapacitors. However, when the change in demand is high in slow cycle and low in fast cycle (such as ratio of 100/50 in Fig. 4.10), the cost increases for $N T=3$. In this case, the higher power demand change in slow cycle is satisfied by high energy density systems, Battery, and the use of Ultracapacitors is not necessary for the small change in power demand in fast cycle, rather it increases the total cost. These observations will help identify the use of appropriate number of type of systems and number of each type of system in a HESS for a specific type of power demand fluctuations. 
(a) Number of System of Each Type, ND = 1

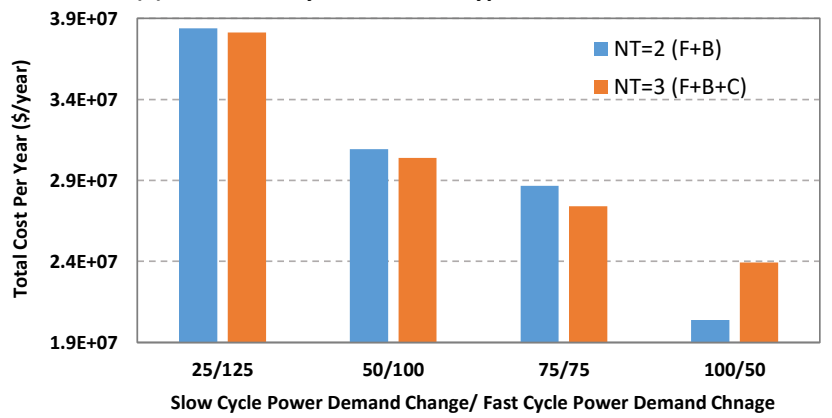

(b) Number of System of Each Type, ND = 2

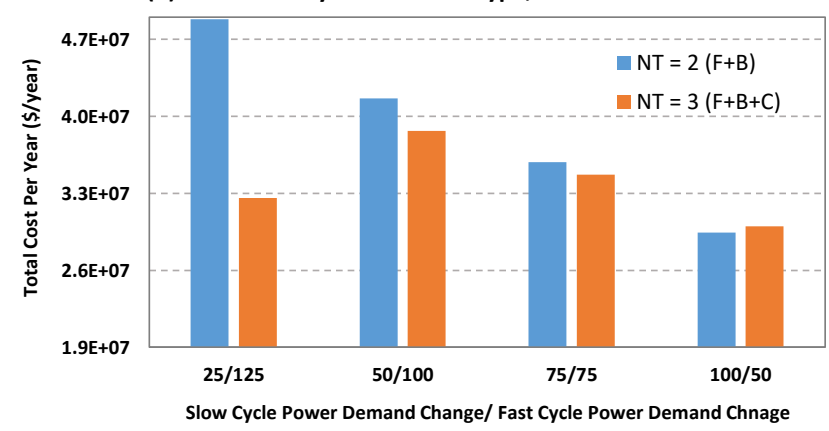

Fig. 4.10. Change in Total Cost per Year for Different Ratios of Power Demand Change in Slow Cycles and Fast Cycles for Number of Type of Systems, $N T=2$ (F+B, Flywheel + Battery; Blue bars) and $N T=3$ $(\mathrm{F}+\mathrm{B}+\mathrm{C}$, Flywheel + Battery + Ultracapacitor; Red bars): (a) Number of Each Type of System, ND = 1 and (b) Number of Each Type of System, $N D=2$.

\section{B. Effects of Power Demand Change Cycle Ratio on Optimized Power and Energy}

Power demand data for four different cases (as described in Section 4.4.1) and two more power demand change ratios with Data Case 2 were used to determine the optimum maximum power and maximum energy for various power demand change ratios of slow cycle and fast cycle. Fig. 4.11 presents the change in optimized maximum power of different type of energy storage systems for $N T=3$, and Fig. 4.12 presents power values of different systems for $N T=2$. Both Figs. 4.11 and 4.12 indicate that for the higher change in power demand in fast cycle, the maximum power of Flywheel is higher and it decreases with decreased magnitude of demand change in fast cycle. Whereas, the maximum power of Battery is high for large change in demand in slow cycle indicating higher or complete contribution of Battery. 


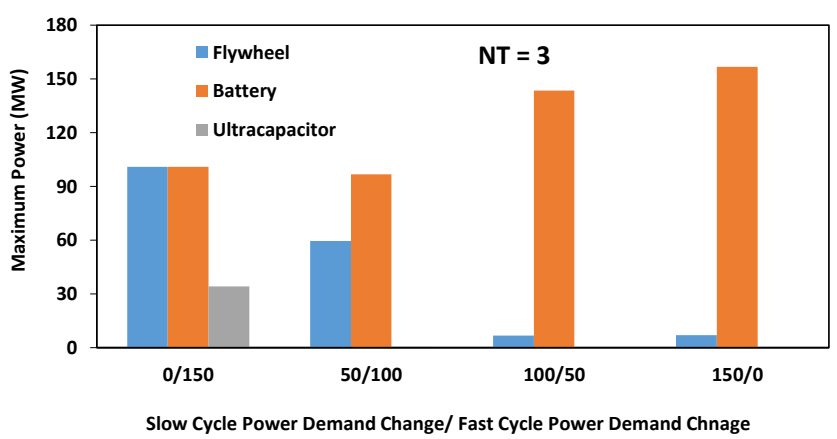

Fig. 4.11. Variation in Optimum Maximum Power (PEmax) of Flywheel, Battery and Ultracapacitor with the Variation of Power Demand Fluctuation for $N T=3$.

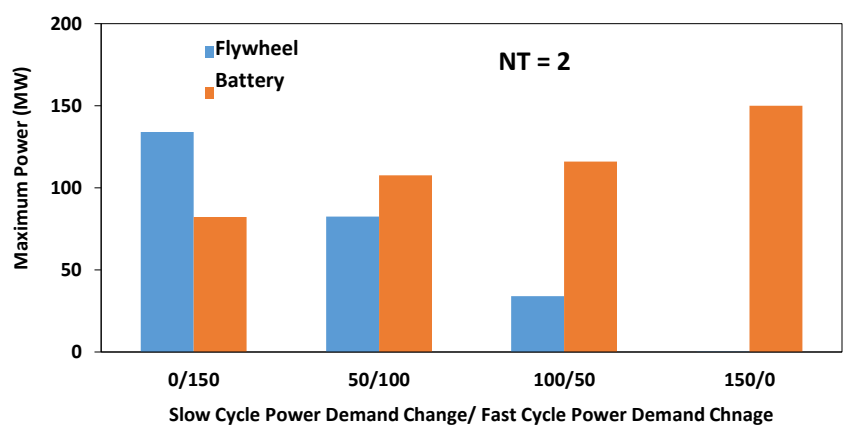

Fig. 4.12. Variation in Optimum Maximum Power (PEmax) of Flywheel, Battery and Ultracapacitor with the Variation of Power Demand Fluctuation for $N T=2$.

Figures 4.13 and 4.14 present the change in optimized maximum energy of different type of energy storage systems with the change in power demand change ratio in slow cycle and fast cycle for $N T=3$ and $N T=2$, respectively. For both $N T$ cases $(N T=3$ and $N T=2)$ the maximum operating energy of Battery is significantly higher than the maximum energy of Flywheel, and the maximum energy of battery decreases with increasing power demand change in slow cycle. Comparing Fig. 4.13 ( $N T=3$; Flywheel, Battery, and Ultracapacitor) and Fig. 4.14 (NT=2; Flywheel and Battery) it is found that the maximum energy from Ultracapacitor is very small. 


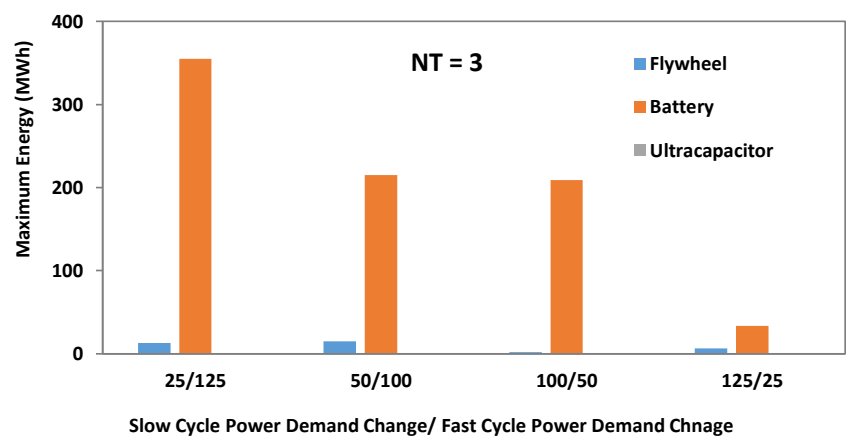

Fig. 4.13. Variation in Optimum Maximum Energy (EEmax) of Flywheel, Battery and Ultracapacitor with the Variation of Power Demand Fluctuation for $N T=3$.

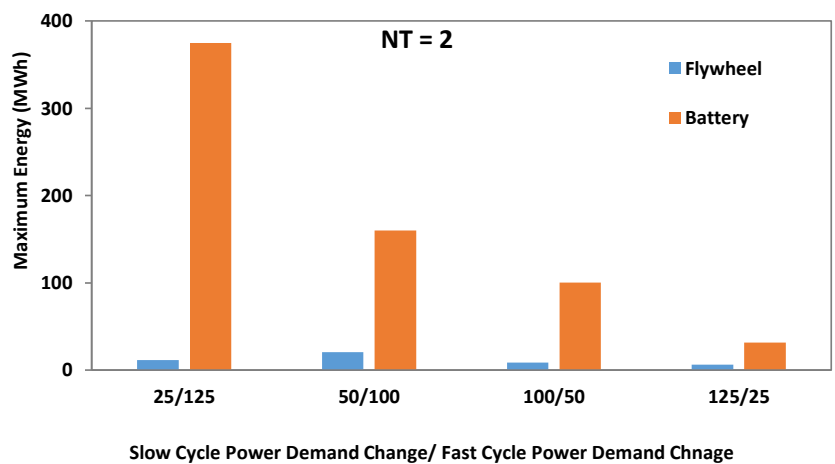

Fig. 4.14. Variation in Optimum Maximum Energy (EEmax) of Flywheel, Battery and Ultracapacitor with the Variation of Power Demand Fluctuation for $N T=2$.

\section{Effects of Power Demand Change Cycle Ratio on DOD and NC}

The optimization solution for the four power demand data cases with number of type of systems, $N T=2$ and 3 also provided the number of cycle $(N C)$ and maximum depth of discharge $(D O D)$ of each type of energy storage systems. Figs. 4.15 and 4.16 present the change in number of cycle per 12 hours of different type of energy storage systems for $N T=3$ and 2, respectively. While number of cycle per 12 hours is constant (one) for Battery in both NT cases for all power demand change ratios, the number of cycle per 12 hours decreases with increasing power demand change in slow cycle for Flywheel and Ultracapacitors for when $N T=3$ and Flywheel, when $N T=2$. Figs. 4.17 and 4.18 present the change in maximum depth of discharge of different type of energy storage systems for $N T=3$ and 2, respectively. The maximum DOD of Flywheel reached to the rated $D O D(99 \%)$ in both $N T$ cases for all power demand change ratios. For $N T=3$, Ultracapacitors 
were used and maximum $D O D$ also reached to the rated $D O D$. For $N T=3$, maximum $D O D$ of Battery was equal to rated $D O D$ when the power demand change ratios were 0/150 and 150/0. However, for power demand change ratio of 50/100 and 100/50 the maximum DOD of Battery was significantly lower ( 20\%). For $N T=2$, maximum DOD of Battery was $\sim 75 \%$ for power demand change ratio of $100 / 50$. These lower DOD of Battery at 100/50 power demand change ratio also lead to lower total cost per year as shown in Fig. 4.10.

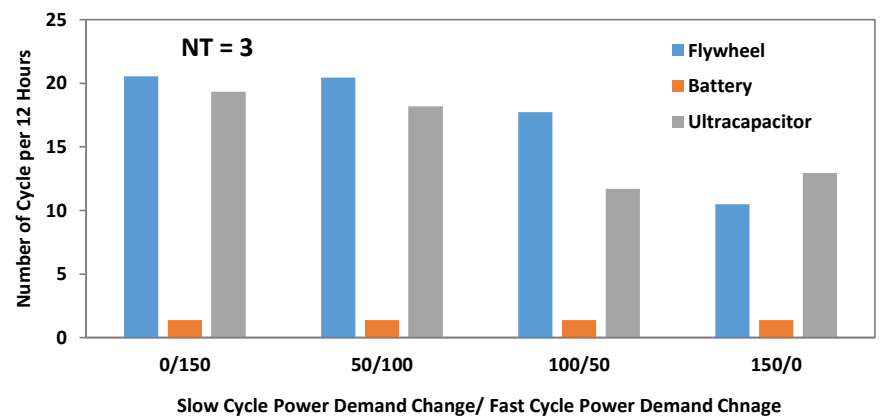

Fig. 4.15. Variation in Number of Cycle per 12 Hours of Each Energy Storage System when HESS Consists of Flywheel, Battery and Ultracapacitor with the Variation of Power Demand Fluctuation for $N T=3$.

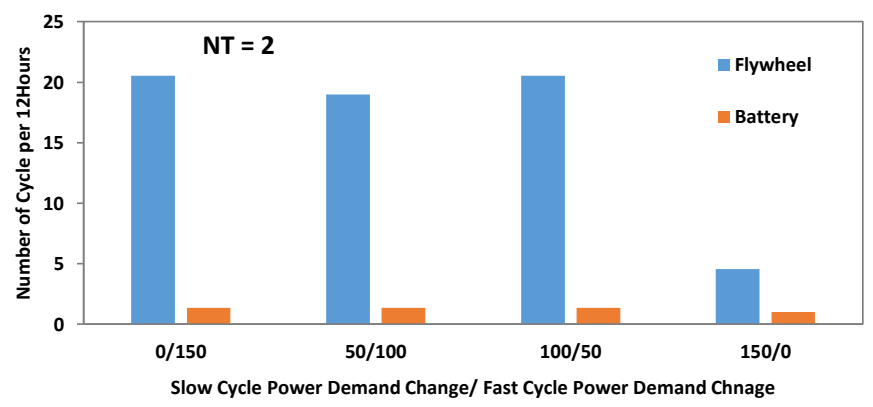

Fig. 4.16. Variation in Number of Cycle per 12 Hours of Each Energy Storage System when HESS Consists of Flywheel and Battery with the Variation of Power Demand Fluctuation for $N T=2$. 


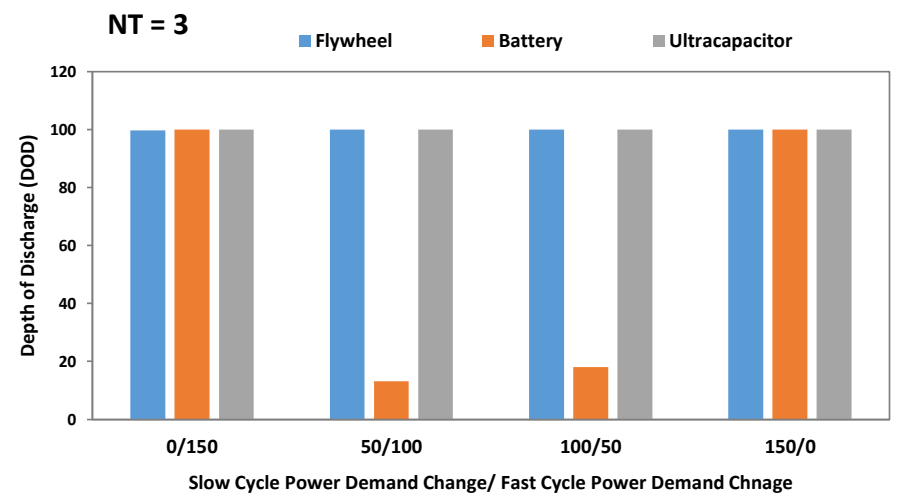

Fig. 4.17. Variation in Depth of Discharge of Each Energy Storage System when HESS Consists of Flywheel, Battery, and Ultracapacitor with the Variation of Power Demand Fluctuation for $N T=3$.

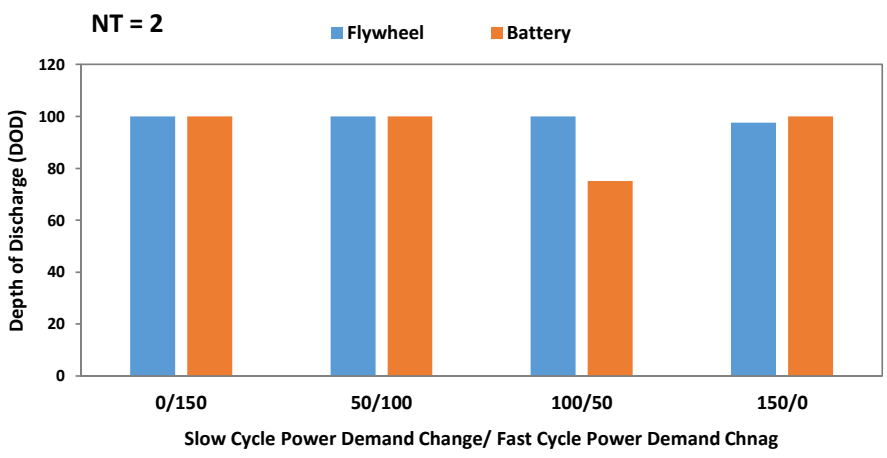

Fig. 4.18. Variation in Depth of Discharge of Each Energy Storage System when HESS Consists of Flywheel and Battery with the Variation of Power Demand Fluctuation for $N T=2$.

\subsection{Sensitivity Analysis}

Sensitivity analyses were performed to determine the effects various parameters of the proposed HESS on the total minimized cost per year using Data Case 1 power demand data. In each analysis, one parameter was varied while all other parameters were kept constant. These analyses were performed for $1 / 50^{\text {th }}$ of the one-day Ontario Power demand data. The parameters for which sensitivity analysis were performed are follows: 

a) Capital Cost ( $A_{-}$Cost) of each type of systems
b) Power Cost (B_Cost) of each type of systems
c) Energy Cost (C_Cost) of each type of systems

Fig. 4.19 shows the pattern of effects of $A_{-}$cost, B_cost and C_cost of Flywheel system on the total cost per year of the HESS.

(a) A Cost

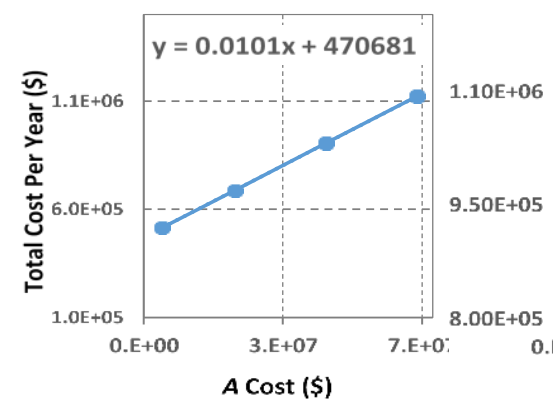

(b) B Cost

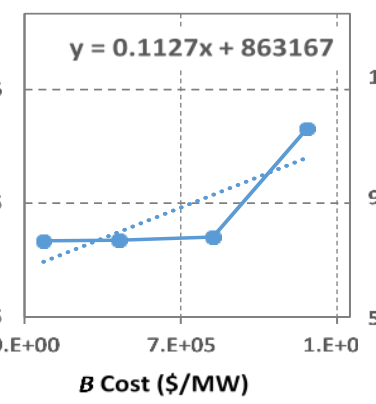

(c) $C$ Cost

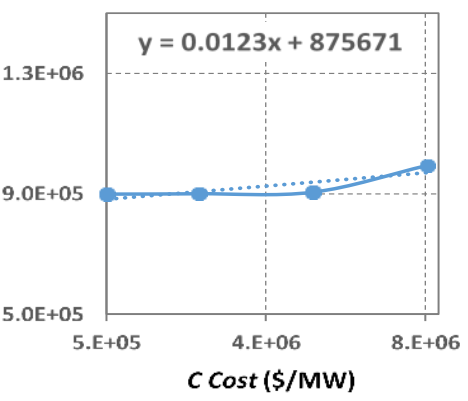

Figure 4.19. Variation of Total Cost per Year with Varying Cost $\left(A_{-}\right.$Cost) Parameters of Flywheel Systems. (Power Data Scaled Down to $1 / 50^{\text {th }}$ )

Table 4.3 presents a summary of the effects of various cost parameters ( $A \_$Cost, $B \_C o s t$, C_Cost) of different storage systems on the total cost per year.

Table 4.3: Impacts of Various Cost Parameters of Different Storage Systems on the Total Cost of HESS

\begin{tabular}{|l|l|l|l|}
\hline $\begin{array}{l}\text { Cost } \\
\text { Parameters }\end{array}$ & Li-lon Battery & Flywheel & Ultracapacitor \\
\hline A_Cost & Medium & Medium & Medium \\
\hline B_Cost & Medium & High & Very Low \\
\hline C_Cost & Very Low & Medium & Very low \\
\hline
\end{tabular}




\subsection{Chapter Summary}

The results and analysis of this thesis work have been presented in this chapter and can be summarized with the following points:

1. Three optimization solvers 'Fmincon', 'Patternsearch' and 'Genetic Algorithm' in MATLAB were implemented. Fmincon solver and Genetic Algorithm were found to provide acceptable solutions and Fmincon was faster.

2. Two different data cases were utilized. In data case 1 real power demand data of Ontario (scaled down to $1 / 50^{\text {th }}$ ) were used. In data case 2 power demand data were created with various magnitudes of power demand change in slow and fast demand change cycle.

3. A one-day 5 minute interval Ontario power demand data were used by scaling down to $1 / 50^{\text {th }}$ in data case 1 analysis. A best-fit line through the demand data was considered as the reference power curve. Effects of number of types systems, number of system in each type, standard deviation and frequency of power demand change, and Cycle life constant on the total cost were determined.

4. The solution of the problem provided maximum operation power and energy, and the distribution of power and energy by different types of storage systems by minimizing the total per year cost. Lower standard deviation of power demand, higher frequency of demand change, lower number of system, higher number of types of system, higher Flywheel and Battery cycle life constant, all contributed to lower total cost per year.

5. Sensitivity analyses were performed for various parameters and their effects on the optimum total cost per year were determined. For HESS combination comprising $N D=1$ and $N T=2$, proved to cost the least indicating that for the selected power data one Battery and one Flywheel system together would be most economical.

6. In data case 2 synthetic power demand data were created with different magnitude of power demand change in slow and fast demand change cycles. The optimization problem solutions for this case indicated that the total cost per year decreased with increased power demand change in slow cycle. The Battery maximum power increased and maximum energy decreased with increased power demand change in slow cycle. In all 
power demand change ratio, the Battery was required to operate at higher maximum energy compared to Flywheel and Ultracapacitor.

7. Inclusion of Ultracapacitor in HESS caused decreased total cost per year when the power demand change in slow cycle decreased up to the power demand change in slow and fast cycle ratio of $75 / 75$, and was found to be beneficial. After this ratio Battery contributed more to the power and energy demand, and the total cost increased for adding Ultracapacitor due to the constant capital cost.

8. These observations indicate that economical design of HESS depends on the power demand data characteristics, and the solutions of the optimization problem for various power demand data can help identifying important factors that lead to lower total cost, such as higher number of types of systems, lower maximum DOD and lower number of cycle, higher change power demand in slow demand cycle.

9. We conclude that the least costing HESS configuration was: Number of types of systems, $N T=2$ with Flywheel and Battery, and Number of systems of each type, $N D=1$, for both power demand data cases. 


\section{CHAPTER 5}

\section{CONCLUSIONS AND RECOMMENDATIONS}

\subsection{General}

This chapter presents chapter-wise summary of all the chapters, key findings (important discovery) and contributions of this research work, and the recommendations for future work.

\subsection{Chapter-wise Summary}

\subsubsection{Chapter 1: Introduction}

a) In this chapter the problem was introduced, motivation and objective of the work were presented.

\subsubsection{Chapter 2: Literature Review}

a) A comprehensive literature survey on various energy storage systems was conducted. Lead-acid battery, Li-Ion battery, Flywheel, and Supercapacitor received special focus as these elements have been utilized in the proposed hybrid energy storage system (HESS) in this thesis.

b) The working principles, classification, characteristics, specifications, and grid scale applications of these storage systems were discussed.

c) The current state of the technologies and their potential applicable roles in the proposed HESS of this work were explained. The research showed that there is lack of knowledge regarding optimization of hybrid energy storage system in grid scale as well as effect of cycle life of each energy storage system of HESS.

\subsubsection{Chapter 3: Proposed Model and Formulation}

a) The objective function and the related constraints of an optimization problem for a proposed hybrid energy storage system (HESS) were created through research and 
development, where the objection function was to minimize the total asset cost per year by optimizing the maximum operation power and energy of all the storage systems comprising the HESS.

b) The objective function included independent cost parameters, such as capital cost, per MW power cost, and per MWh energy cost, and was subjected to constraints related to specifications of the selected type of storage systems, such as rated power capacity, rated energy capacity, rated and allowed depth of discharge (DOD), ramp rate, number of life cycle at rated DOD.

c) The storage systems of the proposed HESS were also required to satisfy the additional power and energy required by the grid at any time.

\subsubsection{Chapter 4: Analyses and Results}

a) Three optimization solvers 'Fmincon', 'Patternsearch' and 'Genetic Algorithm' in MATLAB were implemented. 'Patternsearch' did not provide satisfactory results. Between Fmincon and Genetic Algorithm, Fmincon was found to be faster.

b) Two data cases were considered for the solution of the problem.

c) For data case 1, a one-day 5 minute interval Ontario power demand data were used in analysis by scaling down to $1 / 50^{\text {th }}$. The optimum solution provided the maximum operation power, maximum energy, and the number of type of systems (e.g., Li-lon battery, Flywheel, and Ultracapacitors), and number of cycle, maximum depth of discharge.

d) Sensitivity analyses were performed for various parameters and their effects on the optimum total cost per year were determined. For HESS combination comprising $N D=1$ and $N T=2$, proved to cost the least indicating that for the selected power data one Battery and one Flywheel system together would be most economical.

e) For data case 2, the input power demand data were created with various magnitude of power demand change in slow and fast demand change cycles.

f) The optimum solutions using data case 2 indicated that the total cost per year decreased with increased power demand change in slow cycle. The Battery maximum power 
increased and maximum energy decreased with increased power demand change in slow cycle. In all power demand change ratios, the Battery was required to operate at higher maximum energy compared to Flywheel and Ultracapacitor.

g) The least costing HESS configuration was: Number of types of systems, $N T=2$ with Flywheel and Battery, and Number of systems of each type, $N D=1$, for both power demand data cases.

\subsection{Contributions: Key Findings and Important Discovery}

This work contributes to the general power system area, especially to the hybrid energy storage systems at grid level. The specific contributions are listed below:

a) Developed an optimization formulation with an objective function to minimize the annual asset cost of HESS along with a set of constraints through research and development that can design a hybrid energy storage system (HESS) considering multiple types of storage systems to provide the desired power and energy characteristics.

b) Analysis of data shows that, for power output requirements, a combination of energy storage system types provides the least annual asset cost in comparison to using multiple systems of any one type, proving the hypothesis that HESS are suitable for certain grid scale applications.

\subsection{Recommendations for Future Work}

Some recommendations for the future work are listed below:

1. The proposed HESS model and the developed analysis and solution tool can be applied for peak shaving.

2. For the synthetic power demand dataset, more variations in demand fluctuation types can be included to determine the performance of the proposed HESS 
3. If available, 1 minute interval power demand data can be analyzed with the developed tool for more precise outcome.

4. In the analysis, similar types of energy storage systems with different power and energy ratings and cost parameters can be used to identify the effects of the power and energy ratings of the systems.

5. In addition to the storage systems used in the analysis of this work, other types of storage systems can be incorporated to make the model and developed analysis tool useful for more versatile power management and quality improvement applications. 


\section{REFERENCES}

A. A. Akhil, G. Huff, A. B. Currier, B. C. Kaun, D. M. Rastler, S. B. Chen, A. L. Cotter, D. T. Bradshaw, W. D. Gauntlett, "DOE/EPRI 2013 Electricity Storage Handbook in Collaboration with NRECA," Sandia National Laboratories, California, July, 2013.

AAPPC (AA Portable Power Corp), "Battery Knowledge," Website visited on May 31, 2015.

Website:http://www.batteryspace.com/batteryknowledge.aspx

A. L. Allegre, R. Trigui, A. Bouscayrol, "Different energy management strategies of hybrid energy storage system (HESS) using batteries and supercapacitors for vehicular applications", Proc. 6th IEEE Vehicle Power Propulsion Conference (VPPC 2010), Lille, pp.1 -6 2010

A.S. Anees, "Grid integration of renewable energy sources: Challenges, issues and possible solutions", Power Electronics (IICPE), 2012 IEEE 5th India International Conference on, page(s): 1 - 6, 2012.

M.F. Ashby, J. Polyblank, "Materials for Energy Storage Systems- A white paper," Granata Design, January, 2012.

BET (Battery and Energy Technologies), "Capacitors and Supercapacitors", Electropedia, website visited on May 31, 2015.

Website: http://www.mpoweruk.com/supercaps.htm

J. Bird, "Electrical and Electronic Principles and Technology," Third edition, Elsevier Ltd., The Netherlands, 2007.

V.A. Boicea, "Energy Storage Technologies: The Past and the Present", Proceeding of IEEE, vol. 102, issue. 11, pp. 1777-1794, 2014.

F. A. Bhuiyan, A. Yazdani, "Energy Storage Technologies for Grid-Connected and Off-Grid Power System Applications", in IEEE Electrical Power and Energy Conference, 2012.

BPC (Beacon Power Corporation), "Frequency Regulation Compensation in the ISO/RTO Markets," May 26, 2010.

N. Brown, "How Energy Storage Works", Report from KOMPULSA, website visited on May 30, 2015.

Website: http://www.kompulsa.com/energy-index/energy-storage/

P.C. Butler, J.T. Crow, P.A. Taylor, "Battery evaluation methods and results for stationary applications," Telecommunications Energy Conference, INTELEC 97, 19th International, pp. 311-318, Melbourne, 1997.

R. Cardenas, R. Pena, M. Perez, J. Clare, G. Asher, P. Wheeler, "Power Smoothing Using a Flywheel Driven by a Switched Reluctance Machine," Industrial Electronics, IEEE Transactions on (Volume:53, Issue: 4 ), June, 2006.

R. Carnegie, D. Gotham, D. Nderitu, P. V. Precke, "Utility Scale Energy Storage Systems:Benefits, Applications, and Technologies," From State Utility Forecasting Group, June, 2013.

CG (Capacitor guide.com), "Supercapacitor", website visited on May 31, 2015.

Website: http://www.capacitorguide.com/supercapacitor/ 
Q. Chen, X Chen, L. Nia, Z. Li, Y. Liao, J. Xu, "Optimization smoothing control of large-scale wind farm based on hybrid energy storage," Power System Technology (POWERCON), 2014 International Conference on, pp. $2871-2877$, Chengdu, 2014

N. Dang, H. Tajik, N. Dutt, N. Venkatasubramanian, E. Bozorgzadeh, " Orchestrated application quality and energy storage management in solar-powered embedded systems", $16^{\text {th }}$ International Symposium on Quality Electronic Design (ISQED), pp. 227-233, March, 2015.

M. I. Daoud, A. Khalik, A.S. Massoud, A. Ahmed, N.H. Abbasy, "On the development of flywheel storage systems for power system applications: A survey," Electrical Machines (ICEM), 2012 XXth International Conference on, Marseille, pp. 2119-2125, September 2012.

P. Deepthi, R. S. Rani, "Power Smoothing of Large Solar PV Plant using Hybrid Energy Storage," International Journal of Scientific Engineering and Technology research, vol.04, Issue.16, pp. 2901-2906 June, 2015.

P. Denholm, E. Ela, B. Kirby, M. Milligan, "The Role of Energy Storage with Reneable Electricity Generation," National Renewable Energy Laboratory, Colorado, Report no: NREL/TP6A247187, January, 2010.

ECOFYS, "Energy Storage Opportunities and Challenges: A West Coast Perspective White Paper," April 4, 2014.

EM (EzineMark.com), "Advantages and Disadvantages of Lead Acid Batteries", website visited on July 5, 2015. Website:http://lead.ezinemark.com/advantages-and-disadvantages-of-lead-acid-batteries3229db78a14.html

EPRI (Electric Power Research Institute), "Demonstration Initiative for a Grid Support Energy Storage System Using Li-Ion Technology: Phase I Report," report no: 1025574, 31 July, 2012.

ES (EngineeringShock), "The Forever Rechargeable VARIABLE Super Capacitor Battery," Instructables. Website visited on May 31, 2015.

Website:http://www.instructables.com/id/The-Forever-Rechargeable-VARIABLE-Super-Capacitor-/

A. Etxeberria, I. Vechiu, H. Camblong, J. Vinassa, and H. Camblong, "Hybrid energy storage systems for renewable energy sources integration in microgrids: A review," in Proc. IEEE IPEC, Oct. 2010, pp. 532537.

A. Etxeberria, I. Vechiu, S. Baudoin, H. Camblong, J. Vinassa, "Control of a hybrid energy storage system using a three level neutral point clamped converter, "38th Annual Conf. of the IEEE Ind. Elec. Society, IECON 2012, pp. 3400-3405, 2012.

FARADIGM, An Initiative of Aartech Solonics, "What are the disadvantages of ultracapacitors", website visited on May 31, 2015.

Website:http://www.faradigm.com/faqs/ultracapacitors/What_are_the_disadvantages_of_ultracap acitors.html

M. E. Glavin, W.G. Hurley, "Ultracapacitor/ battery hybrid for solar energy storage", IEEE Conference on Universities Power Engineering, Page(s): 791-795, September 2007.

M. Greenleaf, O. Dalchand; H. Li ; J.P. Zheng, "A Temperature-Dependent Study of Sealed Lead-Acid Batteries Using Physical Equivalent Circuit Modeling With Impedance Spectra Derived High Current/Power Correction", IEEE Transactions on Sustainable energy, vol. 6, Issue. 2, pp. 380-387, January 20, 2015. 
N. E. Ghossein, J.P. Salameh, N. Karami, M. El Hassan, M.B. Najjar, "Survey on electrical modeling methods applied on different battery types," Technological Advances in Electrical, Electronics and Computer Engineering (TAEECE), 2015 Third International Conference on, Beirut, pp. 39-44, 2015.

H. Gualous, D. Bouquain, A. Berthon, J M. Kauffmann, "Thermal Study of Supercapacitor serial resistance", Laboratoire d'Electronique, Electrotechnique et Systèmes (L2ES), 2002.

M.A. Guerrero, E. Romero, F. Barrero, M. I. Milanés, E. González, "Supercapacitors: Alternative Energy Storage Systems," Przegląd Elektrotechniczny, vol: 85(10), pp: 188-195, 2009.

R. Gupta, N. K. Sharma, P. Tiwari, A. Gupta, N. Nigam, A. Gupta, "Application of energy storage devices in power systems", International Journal of Engineering, Science and Technology, vol. 3, no. 1, pp. 289297, 2011.

M.S. Halper, J. C. Ellenbogen, "Supercapacitors: A Brief Overview," Report no: MP 05W0000272, The MITRE Corporation, McLean, Virginia, March 2006.

P. Harrop, H. Zervos, "Batteries, Supercapacitors, Alternative Storage for Portable Devices 2009-2019 Batteries, capacitors, supercapacitors, fuel cells, alternatives", IDTechEx, Ltd.

T. Horiba, "Lithium-Ion Battery Systems," Proceedings of the IEEE (Volume: 102, Issue: 6), pp. 939-950, June 2014

T.D. Hund, S. Gonzalez, K. Barrett, "Grid-Tied PV system energy smoothing", Photovoltaic Specialists Conference (PVSC), 35th IEEE, pp. 2762-2766, Honolulu, 2010.

IEC (International Electrotechnical Commission), "Electrical Energy Storage-white paper", Switzerland, October, 2010.

Z. Jiancheng, H. Lipei, C. Zhiye, W. Su, "Research on flywheel energy storage system for power quality," Power System Technology, 2002. Proceedings. PowerCon 2002. International Conference on, vol.1, no., pp. 496-499 vol.1, 13-17 Oct 2002.

Q. Jiang, H. Hong, "Wavelet-Based Capacity Configuration and Coordinated Control of Hybrid Energy Storage System for Smoothing Out Wind Power Fluctuations," Power Systems, IEEE Transactions on (Volume: 28, Issue: 2), pp. 1363-1372, 2012.

A. Khaligh, Z. Li, "Battery, Ultracapacitor, Fuel Cell, and Hybrid Energy Storage Systems for Electric, Hybrid Electric, Fuel Cell, and Plug-In Hybrid Electric Vehicles: State of the Art," Vehicular Technology, IEEE Transactions on (Volume: 59 , Issue:6), pp. 2806-2814, 2010.

Y. Kim, Y. Wang, N. Chang, and M. Pedram, "Maximum power transfer tracking for a photovoltaicsupercapacitor_energy system," in ISLPED, pp. 307-312, 2010.

Y. Kim, S. Park, N. Chang, Q. Xie, Y. Wang, M. Pedram, "Networked architecture for hybrid electrical energy storage systems," in DAC, pp. 522-528, 2012.

M. Kintner-Meyer, P. Balducci, W. Colella, M. Elizondo, C. Jin, T. Nguyen, V Viswanathan, Y Zhang, "National Assessment of Energy Storage for Grid Balancing and Arbitrage: Phase 1, WECC," Pacific Northwest National Laboratory (PNNL), repot no. PNNL 21388, Richland, Washington, June, 2012.

B. Kirby, M. Milligan, "A Method and Case Study for Estimating the Ramping Capability of a Control Area or Balancing Authority and Implications for Moderate or High Wind Penetration", WINDPOWER 2005 Conference and Exhibition at Denver, Colorado, May, 2005. 
KTS (Kinetic Traction Systems), "Kinetic Traction Systems - Energy Storage and Voltage Support Systems for Rail Traction Systems," United States of America, website visited on July 2015.

R. B. Laughlin, "Introduction to the Physics of Energy", Stanford University, Course PH240, Fall 2010, website visited on May 30, 2015.

Website: http://large.stanford.edu/courses/2010/ph240/

J. Leadbetter, L. Swan, "Battery storage system for residential electricity peak demand shaving", Energy and Buildings, vol. 55, pp. 685-692, December, 2012.

B. Lian, D. Yu, C. Wang, L. Blond, R.W. Dunn, "Investigation of energy storage and open cycle gas turbine for load frequency regulation," Power Engineering Conference (UPEC), 49th International Universities, pp. 1-6, Cluj-Napoca, 2014.

LPF (Lithium Polymer Information), "Lithium Polymer Battery Technology", website visited on May 31, 2015.

J. Locker, T. Wolfe, "Development of an Ultracapacitor-Based Intermediate Energy Storage System", IEEE Pulsed Power Conference, Page(s):1337-1340, June 2005.

T. Matty, K. Nechev, "Li ion energy storage for pulse power applications," Electromagnetic Launch Technology, 2004. 2004 12th Symposium on, pp. 237-242, May 2005.

S. McCluer, J.F. Christin, "Comparing Data Center Batteries, Flywheels, and Ultracapacitors", Schneider Electric, White Paper 65, Revision2, website visited on May 30, 2015.

Website: http://www.apcmedia.com/salestools/DBOY-77FNCT/DBOY-77FNCT_R2_EN.pdf

B.B. McKeon, J. Furukawa, S. Fenstermacher, "Advanced Lead-Acid Batteries and the Development of GridScale Energy Storage Systems," Proceedings of the IEEE (Volume: 102, Issue: 6), pp. 951-963, 2014

N. Meena, V. Baharwani, D. Sharma, A. Sharma, B. Choudhary, P. Parmar, R.B. Stephen, "Charging and discharging characteristics of Lead acid and Li-ion batteries," Power and Energy Systems Conference: Towards Sustainable Energy, 2014, pp. 1-3, Bangalore.

A. Mirhoseini and F. Koushanfar, "HypoEnergy. Hybrid supercapacitor-battery power-supply optimization for energy efficiency," in DATE, pp. 887-890, 2010.

MT (Maxwell Technologies), "K2 2.7V series Ultracacitor," San Diego, website visited on August 2015. Website: http://www.maxwell.com/products/ultracapacitors/k2-series

T. Nguyen, H. Yoo, H. Kim, "A Flywheel Energy Storage System Based on a Doubly Fed Induction Machine and Battery for Microgrid control," Energies, vol. 8, June, 2015.

A. Ostadi, M. Kazerani, S. Chen, "Hybrid Energy Storage System (HESS) in vehicular applications: A review on interfacing battery and ultra-capacitor units," Transportation Electrification Conference and Expo (ITEC), 2013 IEEE, Detroit, MI, pp. 1-7.

K. Paciura, G.P. Hancke, L. Grzesiak, W. Koczara, "A battery energy storage system for the Hygen electricity generator and power supply system," Africon, 1999 IEEE, vol. 2, pp. 949-954, Cape town, 1999.

I. Papic, "Simulation model for discharging a lead-acid battery energy storage system for load leveling," Energy Conversion, IEEE Transactions on (Volume: 21, Issue: 2), pp. 608-615, June 2006.

P.W. Parfomak, "Energy Storage for Power Grids and Electric Transportation: A Technology assessment," Congressional Research Service, March 27, 2012. 
M. Pedram, N. Chang, Y. Kim, Y. Wang, "Hybrid Electrical Energy Storage Systems", ISLPED' 10, Austin, Texas, USA, August 18-20, 2010.

J. Pegueroles-Queralt, F. D. Bianchi, O. Gomis-Bellmunt, "A Power Smoothing System Based on Supercapacitors for Renewable Distributed Generation," Industrial Electronics, IEEE Transactions on,vol. 62, no. 1, pp. 343-350, 2015.

R. Pena-Alzola, R. Sebastian, J. Quesada, A. Colmenar, "Review of flywheel based energy storage systems", International Conference on Power Engineering, Malaga, May 11-13, 2011.

D. Rastler, Electricity Energy Storage Technology Options: A White Paper Primer on Applications, Costs, and Benefits," Electric Power Research Institute (EPRI), California, Dcember, 2010.

P. K. Ray, S.R. Mohanty, N. Kishor, "Dynamic modeling and control of renewable energy based hybrid system for large band wind speed variation," Innovative Smart Grid Technologies Conference Europe (ISGT Europe), 2010 IEEE PES, pp. 1-6, October, 2010.

T.N. Reddy, M.K. Mishra, S.Srinivas, "Grid interactive combined supercapacitor/battery energy storage system with power quality features," Industrial Technology (ICIT), IEEE International Conference on, pp. 2600-2605, Seville, 2015.

RE (Radio-Electronics.com), "Lead Acid Battery Tutorial", Power management and battery technology, Resources and analysis for electronics engineers, website visited on May 31, 2015.

Website:http://www.radio-electronics.com/info/power-management/battery-technology/lead-acidbattery-tutorial.php

P F. Ribeito, B. K. Johnson, L. Crow, A. Arsoy, Y. Liu, "Energy Storage Systems for Advanced Power Applications", in proceedings of the IEEE, vol. 89, no. 12, December, 2001.

K. Sahay, B. Dwivedi, "Supercapacitors Energy Storage System for Power Quality Improvement: An Overview," Journal of Electrical Systems, 2009.

L. Setyawan, L, X. Jianfang, W. Peng, C. F. Hoong, "Hybridization of energy storages with different ramp rates in DC microgrids," Industrial Technology (ICIT), 2015 IEEE International Conference on, Seville, pp. 1317-1322, 2015.

J. Shen, S. Dusmez, A. Khaligh, "Optimization of Sizing and Battery Cycle Life in Battery/Ultracapacitor Hybrid Energy Storage Systems for Electric Vehicle Applications," Industrial Informatics, IEEE Transactions on (Volume: 10, Issue: 4), pp. 2112-2121, July 2014.

D. Shin, Y. Kim, J. Seo, N. Chang, Y. Wang, and M. Pedram, "Battery-supercapacitor hybrid system for highrate pulsed load applications," in DATE, pp. 875-878, 2011.

D. Shively, J. Gardner, T. Haynes, J. Ferguson, "Energy Storage Methods for Renewable Energy Integration and Grid Support," presented at the Energy 2030 Conference, Atlanta, 2008.

S. C. Smith, P. K. Sen, B. Kroposki, and K. Malmedal, "Renewable energy and energy storage systems in rural electrical power systems: Issues, challenges and application guidelines," in Proc. IEEE Rural Electric Power Conference, May 2010.

S.C. Smith, P.K. Sen, B. Kroposki, "Advancement of energy storage devices and applications in electrical power system", IEEE conference on Power and Energy Society General Meeting - Conversion and Delivery of Electrical Energy in the 21st Century, pp. 1-8, 2008. 
T. Siostrzonek, S. Pirog, M. Baszynski, "Energy storage systems the flywheel energy storage", $13^{\text {th }}$ annual IEEE conference on Power Electronics and Motion Control, pp. 1779-1783, 2008.

S. Teleke, "Energy Storage Overview: Applications, Technologies and Economical Evaluation," Quanta Technology, Raleigh, NC, August, 2014.

A. Ter-Gazarian, "Energy Storage for Power Systems", Peter Peregrinus Ltd on behalf of the Institution of Electrical Engineers, London, United Kingdom, 1994.

K. J. Tseng, S. Zhang, T. D. Nguyen, "On the modelling and control of a novel flywheel energy storage system", IEEE International Symposium on Industrial Electronics (ISIE), Bari, July 4-7, 2010.

M. Uno, "Supercapacitor-Based Electrical Energy Storage System", Energy Storage in the Emerging Era of Smart Grids, ed. R. Carbone, INTECH, Japan. 2011.

http://cdn.intechopen.com/pdfs-wm/20362.pdf

US DOE (Department of Energy), "Grid Energy Storage," December 2013.

Y. Wang, Y. Kim, Q. Xie, N. Chang, and M. Pedram, "Charge migration efficiency optimization in hybrid electrical energy storage (HEES) systems," in ISLPED, 2011, pp. 103-108.

G. Wang, M. Ciobotaru, V.G. Agelidis, "Power Smoothing of Large Solar PV Plant Using Hybrid Energy Storage," Sustainable Energy, IEEE Transactions on, page(s): 834 - 842 Volume: 5, Issue: 3, July 2014.

T. Weiqing, S. Wen, D. Chen, "Research on Super-Capacitor and Battery Hybrid Energy Storage System Applied in Micro-grid," Control Engineering and Communication Technology (ICCECT), International Conference on, page(s): 157 - 160, 2012.

X. Zhengping, B. Parkhideh, D. Bhattacharya, "Improving distribution system performance with integrated STATCOM and supercapacitor energy storage system," IEEE Conference on Power Electronics Specialists, Page(s):1390 - 1395, June 2008.

H. Xiaoliang, J. M. A. Curti, H. Yoichi, "Energy management strategy with optimized power interface for the battery supercapacitor hybrid system of Electric Vehicles", 39th Annual Conference of the IEEE Industrial Electronics Society, IECON, Vienna, 2013.

B. Xie, P. Zou, C. Yang, "Ultrahigh power graphene based supercapacitor," Electronic Packaging Technology (ICEPT), 2015 16th International Conference on, China, pp. 1211-1214, $2015 a$.

Q. Xie, Y. Kim, D. Baek, Y. Wang, M. Pedram, N. Chang, "Efficiency-driven design time optimization of a hybrid energy storage system with networked charge transfer interconnect", in Design, Automation \& Test in Europe Conference \& Exhibition (DATE), pp. 1607-1610, 2015b.

Q. Xie, Y. Wang, Y. Kim, N. Chang, and M. Pedram, "Charge allocation for hybrid electrical energy storage systems," in CODES+ISSS, pp. 277-284, 2011.

Q. Xie, Y. Wang, M. Pedram, Y. Kim, D. Shin, and N. Chang, "Charge replacement in hybrid electrical energy storage systems," in ASP-DAC, pp. 627-632, 2012.

Q. Xie, X. Lin, Y. Wang, M. Pedram, D. Shin, N. Chang, "State of Health Aware Charge Management in Hybrid Electrical Energy Storage Systems", in Design, Automation \& Test in Europe Conference \& Exhibition (DATE), pp. 1060-1065, March, 2012.

Y. Ye, R. Sharma, P. Garg, "An integrated power management strategy of hybrid energy storage for renewable application," Industrial Electronics Society, IECON 2014 - 40th Annual Conference of the IEEE, Dallas, pp. 3088-3093. 
F. Zhang, Y. Yang, C. Ji, W. Wei, "Power management strategy research for DC microgrid with hybrid storage system," DC Microgrids (ICDCM), IEEE First International Conference on, pp. 62-68, Atlanta, 2015.

D. Zheng, D. Wei, W. Zhang, Z. Meng, "The study of supercapacitor' transient power quality improvement on Microgrid," PowerTech, IEEE Eindhoven, pp.1-5, 2015.

L, Zhou, W. Liu, X. Tang, "Direct power control method for grid-connected flywheel array energy storage system", International Conference on Power System Technology (POWERCON), Chengdu, October 2022, 2014.

K. Zhuge, M. Kazerani, "Development of a hybrid energy storage system (HESS) for electric and hybrid electric vehicles," Transportation Electrification Conference and Expo (ITEC), 2014 IEEE, Dearborn, MI, pp. 1-5, 2014. 